University of Rhode Island

DigitalCommons@URI

Open Access Dissertations

2002

\title{
An Examination of the Nature of Reading Fluency
}

Emily D. Russell

University of Rhode Island

Follow this and additional works at: https://digitalcommons.uri.edu/oa_diss

\section{Recommended Citation}

Russell, Emily D., "An Examination of the Nature of Reading Fluency" (2002). Open Access Dissertations. Paper 1014.

https://digitalcommons.uri.edu/oa_diss/1014

This Dissertation is brought to you for free and open access by DigitalCommons@URI. It has been accepted for inclusion in Open Access Dissertations by an authorized administrator of DigitalCommons@URI. For more information, please contact digitalcommons-group@uri.edu. 


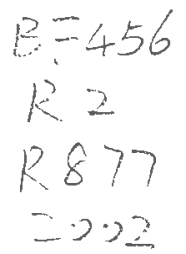

AN EXAMINATION OF THE NATURE OF READING FLUENCY BY EMILY D. RUSSELL

A DISSERTATION SUBMITTED IN PARTIAL FULFILLMENT OF THE REQUIREMENT FOR THE DEGREE OF DOCTOR OF PHILOSOPHY IN PSYCHOLOGY 


\begin{abstract}
The present study attempted to investigate the underlying cognitive and linguistic skills necessary for three different aspects of reading fluency: rate, phrasing, quality of expression. The variance accounted for by each of these skills on measures of reading comprehension was also evaluated. Oral reading skills of thirdand fourth-grade normal readers were assessed on narrative passages within each participant's independent reading level (i.e., fewer than two percent word reading errors). Results indicated similarities in the cognitive and reading skills necessary for rapid reading and appropriate phrasing. Specifically, word recognition was the strongest predictor in both cases. However, oromotor accuracy and rapid serial naming also accounted for significant portions of variance in both reading rate and phrasing skill, after controlling for age and/or independent reading level. In addition, working memory was a significant predictor of reading rate. Linguistic measures of syntax knowledge and listening comprehension did not contribute significantly to variance in phrasing. The assessment tool created to evaluate quality of phrasing and expression is presented. Limitations of this study and suggestions for future research also are discussed.
\end{abstract}




\section{ACKNOWLEDGMENTS}

This research was supported, in part, by a grant from the National Institute of Child Health and Human Development (Grant HD-01994) to Haskins Laboratories. I would like to thank Anne Fowler, Hollis Scarborough, and Donald Shankweiler at Haskins for giving their time and assistance to the development of this project.

In addition, I would like to thank Kim Pristawa and Jennifer Sciengaj for their help and conscientious involvement during the data collection phase of this study. The wonderful third- and fourth-grade students and staff at Coleytown Elementary School, who generously gave their time and enthusiasm, must also be acknowledged. I also would like to thank my major professor, Susan Brady. The importance of the encouragement, insight, and late nights and weekends you have given me cannot be overestimated. I am very grateful.

Finally, I would like to thank my parents, Bob and Susan Russell, who still do whatever is necessary to help me meet and overcome life's challenges. 
TABLE OF CONTENTS

Abstract

Acknowledgements

ii

List of Tables

iv

List of Figures

V

Chapter I - Introduction

Chapter II - Method

Chapter III - Results

Chapter IV - Discussion

Appendices

Bibliography 


\section{LIST OF TABLES}

Table 1 Demographic Characteristics of Participants Who Met Study Criteria 28

Table 2 Prosodic Quality Scale for Reading 34

Table 3 Descriptive Statistics for Passage Reading, Cognitive, and Linguistic Measures $\quad 50$

Table $4 \quad$ Factor Loadings for Passage Reading Variables 54

Table 5 Factor Loadings for Passage Reading, Cognitive, and Linguistic Measures

Table 6 Hierarchical Multiple Regression Analysis of

Predictors of Reading Rate

Table $7 \quad$ Hierarchical Multiple Regression Analysis of Predictors of Phrasing

Table 8 Conversion of Continuous to Categorical Variables

Table 9 Chi Square Analysis of Comprehension 


\section{LIST OF FIGURES}

Figure $1 \quad$ Scatterplot of Residuals of Regression Model Predicting Reading Rate

Figure 2 Scatterplot of Residuals for Phrasing Regression Model

Figure 3 Scatterplot of Residuals of Expression Regression Model 


\section{Chapter I}

\section{INTRODUCTION}

For several decades, researchers in reading and literacy development have placed a heavy emphasis on the importance of phonological awareness and the alphabetic principle as precursors to early reading development (e.g., Ball, 1993; Liberman, Shankweiler, \& Liberman, 1989; Liberman, Shankweiler, Fischer, \& Carter, 1974) . Intervention research also has demonstrated that intensive and systematic instruction in phonological awareness and phonics leads to improvements in basic reading skills such as decoding, word recognition, and even spelling (e.g., Ball \& Blachman, 1991; Torgesen, Wagner, \& Rashotte, 1997). What is less well understood is how more advanced reading skills evolve. Clinical descriptions (e.g., Chomsky, 1976) and research (e.g., Torgesen, Rashotte, \& Alexander, 2001) have indicated that children who experience problems during the early stages of reading acquisition may, even if they receive appropriate instruction and benefit from it, demonstrate problems beyond accurate word recognition as they progress through school

Among the most significant of these problems is a lack of reading fluency. Some children who develop successful strategies for decoding and word recognition are plagued by slow, effortful, word-by-word reading as they attempt to acquire better reading skills. Several studies have identified and examined groups of children with adequate decoding and word recognition skills, but who demonstrate disfluent oral reading (Dowhower, 1987; Lovett, 1984; Wolf, 1997). It has been suggested that these children may represent a transitional period within a developmental progression of children with reading disabilities (Lovett, 1984). Others hypothesize that there may be a 
separate underlying problem with rate-related processes (Wolf \& Bowers, 1999). Once children with reading difficulties have achieved decoding accuracy, there is often still a struggle to become rapid, automatic, and fluent readers in the later stages of reading acquisition.

The underlying reading and cognitive skills necessary for fluency to develop are not yet well understood. Though a small number of studies have attempted to explore factors in fluency, a clear understanding of the cognitive and reading skills that contribute to individual differences in the emergence of fluent reading has not been achieved and should be explored (National Institute of Child Health and Human Development (NICHD), 2000). This type of information would be useful for several reasons, among the most important of which are to identify children at risk for disfluent reading and to guide intervention efforts.

Nonetheless, the need for treatment of fluency problems has spawned the development of multiple methods to increase reading fluency. These include programs in which children are simply encouraged to increase their amount of independent and recreational reading. Often these approaches are not formal, but are targeted at increasing amount of practice and exposure to print (NICHD, 2000). Also, more explicit intervention strategies have been developed whereby children repeatedly read text aloud with guidance and some type of feedback. For example, students may practice reading isolated words taken from passages before reading the passage itself. Other approaches include directions to repeatedly read passages themselves, listen to models read passages emphasizing the most appropriate prosodic features, read out loud while a model is reading simultaneously, and others (see Meyer \& Felton, 1999, for a review of 
intervention and teaching methods). The research investigating the efficacy of these procedures has been somewhat inconsistent as to which methods are the most effective and why (NICHD, 2000). The central purpose of this study is to expand our knowledge of the underlying reading skills and cognitive abilities necessary for reading fluency. This may subsequently provide insight into the methods of fluency training that should logically be more effective than others based on these core factors.

\section{Why Is Fluent Reading Important?}

One reason to focus on reading fluency is because of the link many researchers have found between reading comprehension and reading fluency. In theory, when basic reading skills are slow and inaccurate, they require a great deal of effort and concentration, limiting the amount of attention the reader has available to focus on the meaning of the text (Ehri \& McCormick, 1998; Laberge \& Samuels, 1974; Perfetti \& Hogaboam, 1975). Empirically, this hypothesis has been supported by researchers who have found associations between simultaneous increases in fluency and comprehension. In studies conducted by Levy, Albello, and Lysynchuk (1997), the reading comprehension performance of fourth-grade poor readers, as measured by their ability to both retell stories and to answer a list of questions, was better after training the children to read words from the passage in isolation before actually reading the passage. This training led to improvements in rate and accuracy that subsequently allowed for better comprehension of the passage. A crucial component during the training phase of this study was that the participants were required to attain a reading rate of one second per word or less. When this criterion was not established, improvements in comprehension 
were not noted. The authors hypothesized that proper timing of the availability of words is what enabled the higher level language comprehension processes to take place.

Similar results have been reported by several other researchers. For example, Tan \& Nicholson (1997) required seven- to ten-year-old poor readers to read passages after they had been trained to read either words or phrases from those passages, in an effort to increase their ability to read the passage fluently. Again, after the reading, understanding of the passages was measured by the participants' ability to retell the stories and to answer a series of questions. Reading rate and accuracy, as well as comprehension of the passages, were better for children who were trained to read both words and phrases than for control subjects who received no training.

Finally, Fuchs, Fuchs, and Maxell (1988) identified a very strong relationship between reading rate and accuracy and ability to understand connected text. They assessed the silent reading comprehension skills of 70 middle school children with reading disabilities. The participants were administered two, 400 -word passages to read silently, and were then asked to read and identify correct answers to questions about the passages from four choices. In addition, three other measures of reading comprehension were also administered, including oral question and answering, passage recall via retelling, and cloze procedures in which words in the passages were deleted and the students were required to fill in the blanks. Lastly, a measure of each participant's reading rate and accuracy was obtained by calculating the average number of words read correctly per minute for both passages. Analyses of the data indicated that the relationship between rate and accuracy calculations with the initial silent reading comprehension measure was stronger than the relationship between the alternative 
comprehension measures and the original ( .91 and .82 for oral questioning, .70 for retelling, .72 for cloze procedures).

Many have questioned the importance of oral reading of text, since the act of reading silently is a more common practice among skilled readers. To address this concern, Fuchs, Fuchs, Eaton, \& Hamlet (unpublished data, cited in Fuchs, Fuchs, Hosp, \& Jenkins, 2001) asked 365 fourth-graders to read one passage orally and another silently and answer comprehension questions about them. Rate of reading on these passages was assessed by noting the last word read orally at two minutes for the oral passage, and by asking the child to point to the word they were reading at two minutes on the silently read passages. In addition, the participants were asked to complete an additional standardized test of silent reading comprehension. Correlations between silent reading rate with comprehension of the passage read silently and the other comprehension measure were .38 and .47 respectively. However, correlations between the oral reading rate with comprehension of passages read orally and the other comprehension measure were .84 and .80. The differences in these correlations were significant and telling. Based on these data, reading orally does appear to yield stronger relationships with comprehension measures than reading silently. However, certain methodological problems cannot be accounted for, such as the accuracy with which rate was measured on the passages read silently and differences in decoding accuracy that may have occurred between oral and silent reading.

Another reason it is important to focus on reading fluency is because it has an impact on a reader's interest in and motivation to engage in reading activities. If the reading process is difficult and slow, the reader will be less likely to engage in it. In an 
effort to investigate the relationship between early reading experience and later attitudes toward reading, Linn, Stanovich and Stringer (1999) found that quality and knowledge of the alphabetic code in first grade was highly associated with interest in and exposure to print in fourth grade. Furthermore, the effect is cyclical: when the amount of time a child spends reading is limited, so is his or her opportunity to develop better reading skills. Poor readers notoriously spend less time reading than good readers and read less text when they do. This decreased exposure to text contributes to greater differences in many basic reading skills such as orthographic processing and decoding (Stanovich, 1986), and other language skills such as vocabulary development (Anderson, Wilson, \& Fielding, 1988), which in turn negatively impact comprehension.

\section{What is Fluent Reading?}

When people describe fluent reading, they typically are referring to two general types of characteristics. First, estimates of fluency typically are based on the rate and accuracy with which a child recognizes words in text. Here, the emphasis is on the importance of automatic decoding and word recognition. However, the quality of the verbal expression or the prosody that is projected also contributes to how fluently a child appears to be reading. Though many have focused on either one or the other of these two characteristics, Young and Bowers (1995) have suggested that fluency is the result of the integration of decoding speed and the higher level linguistic skills necessary for reading with expression. What follows is a discussion of each of these skills individually and some of the underlying abilities that may contribute to their development. 
Rate and accuracy of word recognition

The concept of automaticity has been a familiar one in the study of cognitive and experimental psychology for many years. Much research has focused on the progression from non-automatic processing of information, defined generally as slow, effortful, and dependent, to the development of automatic processing that is rapid, easy, and autonomous, and on the cognitive skills that underlie that progression (Logan, 1997). The development of automaticity in reading, in particular, has also received a good deal of attention.

In 1974, LaBerge and Samuels raised interest in the idea of rapid and accurate word reading when they emphasized the importance of automaticity in developing reading skills. They proposed a model of automatic information processing in reading that highlighted the importance of attentional resources. The model predicted that to develop reading proficiency, conscious mental energy (i.e., attention) is needed in order to recognize letters, spelling patterns, and whole words. Later, after much learning and practice, attention free (i.e., automatic) identification of individual letters and spelling patterns develops, and automatic word recognition can finally be achieved.

A few years after LaBerge and Samuels' original (1974) automaticity proposal, Samuels (1979) went on to designate three separate stages in the development of automatic word recognition skills. The first is the non-accurate stage in which the child's word recognition skills are slow and inaccurate. The second is the accurate stage consisting of accurate but slow and labored word recognition; therefore, attention is still focused on the process of decoding rather than on comprehending. Finally, there is the 
automatic stage, in which the child can recognize words with ease, allowing attention to be focused on the meaning of the passage.

Interest in the importance of automaticity in reading was also exhibited by Perfetti and Hogaboam (1975) around the same time as Laberge and Samuels (1974). They compared both third-grade good and poor comprehenders and fifth-grade good and poor comprehenders on their abilities to read aloud words on a projection screen as quickly as possible. Results indicated that the good comprehenders at both grade levels were significantly faster at this task than the poor comprehenders at the same grade level, particularly with pseudowords or low frequency English words. From this, they concluded that good comprehenders seem able to decode words more automatically than poor comprehenders, and they hypothesized that these differences resulted from what they called a "shared limited capacity" (p. 468). The basis for their interpretation is similar to LaBerge and Samuels' (1974) proposition, in that the mind is assumed to have limited resources for processing information at a given time. When a child achieves the ability to recognize or decode words automatically, greater resources are hypothesized to be available to focus on the higher level linguistic information in the text, such as semantic and grammatic cues, to aid in comprehension.

Later, Perfetti and Lesgold (1979) elaborated on this idea, referring to the limited capacity model as the "bottleneck hypothesis" (p. 63). A central concept behind the updated theory was that ability to comprehend written material is constrained by limits in working memory. Working memory was conceived as a stage in information processing in which incoming material (e.g., from the text) is analyzed (i.e., decoded, syntactically interpreted, etc.). Working memory was suggested to serve as a limited pathway or 
bottleneck, with negative consequences for comprehension if one of the three following subskills are not automatic: 1) retrieval of knowledge in long term memory; 2) efficient language processing strategies, including an understanding of grammar, syntax, and sentence or phrasal boundaries; and 3) speedy, accurate, and automatic decoding skills. Perfetti and Lesgold underscore issues pertaining to the third subskill, decoding. They note that measuring the accuracy of decoding is not going to reveal the amount of cognitive attention it will require to achieve good comprehension. Rather, measuring decoding speed is also very important.

Finally, Logan (1997) applied concepts from instance theories in cognitive psychology to the acquisition of reading skill. According to Logan, the Instance Theory of Automaticity proposes that the most important cause of learning and subsequent facility with a skill rests on the development of episodic memory traces over time. In order to build up a database of these memory traces, three assumptions must be met. First, for a stimulus to be encoded into memory, it simply must be attended to (i.e., obligatory encoding). This assumption provides the foundation for learning. Intention or desire to learn has little impact on whether something actually is learned. Rather, simple attention to a stimulus is sufficient for learning and memory processes to begin.

Second, attention to a stimulus is sufficient for other related memories already processed and stored to be retrieved and, subsequently, associated with it (i.e., obligatory retrieval). This assumption provides the basis for the manifestation of automaticity when completing a skill. The greater the amount of information that has been encoded and stored for a particular stimulus, the greater the amount of information there is to be recalled with each new experience with that stimulus. 
Finally, the last assumption on which the Instance Theory rests is that each memory of a stimulus is encoded, stored, and retrieved separately (i.e., instance representation). This assumption accounts for the gradual decrease in reaction times as one gains experience with a stimulus. Accordingly, the retrieval process can actually be likened to a race among the different memory traces. The first memory trace to be retrieved is sufficient for performance to take place. What is important, however, is that the more traces that exist, the faster that race will be finished. Therefore, the rate at which a skill is completed will gradually increase as the number of traces increases.

\section{Quality of Verbal Expression}

Several researchers have argued that the acquisition of reading fluency requires more than simply decoding words with speed and accuracy (Allington, 1983; Rasinski, 1989; Schrieber, 1980). The beginning reader also must be able to group words together into meaningful chunks or phrases and to read with appropriate expression.

A brief explanation of the possible methods for judging the quality of a reader's expression seems in order at this point. In a study examining the effects of repeated reading techniques on prosodic quality, Dowhower (1987) describes several features of oral reading that influence prosodic quality. First, there are pausal intrusions, which are inappropriate hesitations within words or within syntactical units. Second, the length of phrases also influences expressiveness, and evidence that students in high reading groups read more words in between pauses than those in lower groups is cited. Another indicator of reading in meaningful phrases is whether the reader engages in appropriate phrasing, which means reading in syntactically and phonologically acceptable phrases. 
Phrase final lengthening, when the last syllable of a phrase is longer than the same syllable in a non-phrase-final position, is another indicator of reading expressiveness. Finally, intonation contour is the pattern of changes in pitch of the speaker's voice; students in lower reading groups have been shown to read with more inappropriate pitch changes.

Additionally, Allington (1983) has also developed an approach for judging prosodic quality that is less quantitative than Dowhower's (1987). He characterizes nonfluent reading as word by word, with no attention to phrases or syntactically appropriate intonations. A more developed reader is able to read in phrases, but with inappropriate intonation in relation to syntax. Finally, a highly developed reader is able to read phrases with fluency, adhering to expressive cues provided by punctuation, and reading with expression that is appropriate for the semantic and syntactic context of the material.

Some have argued (e.g., Schreiber, 1980) that reading with appropriate prosody can be a challenge for any beginning reader because there are few graphic cues available in printed text that might signal how to do this. Young readers with normal reading acquisition seem able to apply what they have learned about phrasing and prosody from oral language to acquire the ability to read with appropriate expression. However, poor readers, for a variety of possible reasons, do not make the transition as easily. One guess, in addition to the limitations induced by weak decoding skills, is that poor readers do not rely sufficiently on syntactical and morphological cues to guide expressive reading. This may result in poor phrasing or parsing strategies, often seen as one of the primary markers of good expressive reading. 
Indeed, research with adult poor readers indicated that their knowledge of where to parse written sentences was significantly below that of their normal reading peers, particularly as the difficulty level of the text increased (Rasinksi, 1989). However, other research looking at the amount of variance contributed by phrasing skills to overall ratings of prosodic quality yielded more complex findings with regard to the importance of phrasal knowledge. In a sample of fifth-grade, good and poor readers, Young and Bowers (1995) found that phrasing ability made no unique contribution to reading expression in the poor readers, especially after controlling for other factors (word accuracy and reading rate). Conversely, phrasing ability was more important as a predictor of expressive ability with the good readers, but only on passages with relatively difficult text.

This pattern related to text difficulty level has been identified in other studies. In general, many researchers have identified a greater amount of disfluent reading as the level of the text difficulty increases. For example, when a sample of normally fluent elementary school children was required to read passages at different difficulty levels (i.e., one grade below their reading level, at their reading level, and one, two, and three grades above their grade placement), the amount of disfluent reading increased with the higher text levels (Cecconi, Hood, \& Tucker, 1977). However, Young \& Bowers (1995) also explored this issue and found that the results again were more complex than originally thought. In their sample of good and poor fifth-grade readers, the reading rate and accuracy of both groups decreased as text difficulty level increased, and the decline was especially noteworthy for the poor readers, a finding consistent with previous research. However, as far as general prosodic quality or expressiveness was concerned, 
a decrease was only noted in the poor reader groups as difficulty level increased. The ability to read with appropriate expression was not negatively impacted among the good readers as the level of the text difficulty got increased. The difference in the results of these studies appears to result from the fact that Young and Bowers (1995) specified more clearly the separate characteristics that contribute to fluent reading. For good readers, the ability to read with expression is maintained, even when they are reading difficult text, though their rate and accuracy may decline. For poor readers, on the other hand, all aspects of fluency (rate, accuracy, and expression) are hindered by difficult text.

\section{Which Cognitive Abilities Predict Reading Fluency?}

Because there are several components involved in a reader's fluency (rate, accuracy, prosody), there are also likely to be several underlying factors that contribute to each. Thus far, knowledge in this area is scant. The limited research that has been done has examined the relationship fluent reading may have with three specific areas of skill: word recognition and decoding, phonological awareness, and rapid serial naming.

\section{Word Recognition/Decoding}

Not surprisingly, basic word recognition and decoding skills appear to be correlated with the ability to read text quickly and accurately. Several intervention studies have demonstrated that when elementary school children are trained to read lists of words from a passage until they can do so quickly and easily, the speed and accuracy with which they eventually read the connected text significantly improves (Fleischer, 
Jenkins, \& Pany, 1979; Levy, Albello, \& Lysynchuk, 1997; Tan \& Nicholson, 1997; van den Bosch, van Bon, \& Schreuder, 1995).

The importance of previous exposure to words for reading fluency was also demonstrated by Faulkner and Levy (1999), who found that the benefits vary for different kinds of readers. They compared the effects of reading a normal and a scrambled version of a text on later passage reading of that same text with fourth grade and undergraduate good and poor readers. Results indicated that the second readings of the good readers were significantly faster when their first reading had been with a normal text, as opposed to the scrambled version, but the second readings of poor readers improved equally, regardless of whether they read a normal or scrambled text in the first round. It seems that simple exposure to the words, regardless of semantic or syntactic structure, was beneficial to the poor readers' fluency, whereas good readers were only aided when not only the words, but also the semantic and syntactic structure, were the same on each reading. These findings suggest that different factors (word level processing vs. text level processing) may contribute to reading fluency, depending on the individual's reading attainment. Supporting evidence comes from a small study reporting that performance on a measure of isolated word reading fluency was strongly correlated both with reading rate and accuracy for a sample of severely disabled twelve-year-old readers, but not for a sample of their normal-reading peers (Russell, 2000).

Also, in the fluency prediction study mentioned earlier, Young and Bowers (1995) found that fifth-graders' performance on a general measure of word recognition was associated with reading rate, suggesting that this relationship was present even when the words did not come directly from the text being read. Additionally, performance on 
this reading measure was predictive of the child's ability to read with appropriate phrasing and prosody. Yet, according to Young and Bowers (1995), word reading performance was not strongly correlated with text reading accuracy unless the text being read was relatively difficult. As the words in the passage became more difficult, the decoding strategies necessary for sounding out those words became more predictive of the accuracy with which the passages were read. However, on easier passages decoding ability mattered relatively little. This finding further demonstrates the importance of considering the difficulty level of the text: when passages are easy, the relevance of decoding skills is minimized, but when they are harder decoding is still an important predictor of text accuracy.

Phonological Awareness

Phonological awareness also seems to play a role in the development of some aspects of reading fluency. This is to be expected given the strong relationship phonological awareness bears to the development of decoding and word recognition skills. The study by Young \& Bowers (1995) is the only one to examine the relationship between phoneme awareness and fluency specifically. Results indicated that performance on a measure requiring syllable and phoneme deletion made a significant unique contribution to text reading accuracy. However, like decoding measures, performance on the same task was only predictive of scores on measures of passage reading rate as the difficulty level of the text material increases. Also, phoneme awareness seemed to relate very little to the quality of reading expression (Young \& Bowers, 1995). 


\section{Rapid Serial Naming}

Rapid Serial Naming (RSN) tasks require the ability to name a series of items in rows (e.g., often a 5 X 10 matrix) as quickly as possible. The items are usually colors, objects, digits, or letters. Many researchers have reported an association between performance on these tasks and a variety of different types of concurrent reading skills (Denckla \& Rudel, 1972; Snyder \& Downey, 1995; Wolf \& Bowers, 1999). Associations with later reading achievement also have been obtained (Elbro, 1997), particularly on the symbolic naming tasks (i.e., letters and digits), as opposed to those that interact with lexical knowledge (i.e., colors and objects; Decker, 1989; Scarborough \& Domgaard, 1998). The associations between RSN and reading that have been found are thought to be explained by the fact that RSN, like reading, taps both phonological skills, processing speed (Denckla \& Cutting, 1999) and oromotor planning (Snyder \& Downey, 1995).

RSN skills have also been shown to bear a specific relationship to different aspects of reading fluency. Young and Bowers (1995) found that, although it did not significantly contribute to the accuracy with which children read passages, performance on digit naming tasks did make a significant and unique contribution to the quality of the reader's expression and to the speed with which subjects read. In a different study, significant differences between children who had good and poor RSN speeds were found on measures of text reading rate, but again, text reading accuracy scores did not differ significantly (Bowers, Sunseth, \& Golden, 1999). Finally, Bowers (1993) conducted a fluency training study that compared good and poor readers with either fast or slow RSN speeds in each group. One interesting point about this study was the fact that good readers with slow RSN speeds were identified for participation, which calls into question 
the importance of RSN for good reading skills. Regardless, results from that study indicated that the slow RSN subjects of both reading groups did not show improvements in fluency after training as quickly as the fast RSN subjects (Bowers, 1993). The author speculated that the deficit in slow RSN children is so severe that it limits the benefits they can obtain from repeated reading experiences. However, results from a more recent study with a longer training period contradicted Bowers (1993) findings. Levy et al (1997) found that children with slower RSN times showed improvements in fluency more quickly than did children with fast RSN times. These contrasting results may have reflected differences in the severity of the RSN deficits between the two studies. The latter group had less severe deficits and therefore was better able to capitalize on the practice to increase their reading speed. These contrasting results may also reflect how difficult it is to obtain comparable samples with respect to prior instruction, reading skills, etc.

\section{Are There Other Factors That May Be Related To Fluent Reading?}

Evidence suggests that the components of reading fluency, including reading rate, accuracy, and expressiveness, are each associated with specific cognitive and reading abilities such as word recognition and decoding, phonological awareness, and rapid serial naming. What is not well understood, however, are other factors that also may be involved in the development of reading fluency. A multitude of linguistic abilities have been shown to be correlated with general reading skills, and it is logical to assume that many of these may also be implicated in fluent reading performance. Additionally, some researchers have argued that certain non-linguistic abilities, such as general aspects of 
cognitive processing speed, are related to reading. What follows is a discussion of these skills and issues.

\section{Language Comprehension}

The 'Simple Theory' of reading is a framework for discussing reading abilities that was first described by Gough and Tunmer (1986) in an effort to organize and/or reduce the component process of reading into a few basic constructs. They argued that reading comprehension is the product of decoding skills and listening comprehension skills $(\mathrm{D} X \mathrm{LC}=\mathrm{RC})$. It had already been repeatedly demonstrated that both skills, when assessed separately, made unique, significant contributions to reading comprehension. What Gough and Tunmer were adding was that the regression equation of these skills in combination accounts for almost all of the variance noted in reading comprehension.

Keeping this simple theory in mind, many researchers have demonstrated that the relative importance of each of these components varies with the level of the reader's skill. In seven- to nine-year-old children who are still in the early stages of reading acquisition, differences in reading comprehension are closely associated with differences in decoding skill (Shankweiler et al., 1999). However, as decoding skills improve, and thus the child's reading level improves, it appears that differences in reading comprehension become more closely associated with level of language comprehension. If listening comprehension does play a larger role in reading at the later stages of development, it is possible that it is associated with the emergence and maintenance of fluent reading skills, since fluency is also seen later in the reading acquisition process. An exploration of data to support this hypothesis would be informative. 


\section{Verbal Working Memory}

A great deal of evidence has been obtained showing that poor readers have deficient verbal memory skills. Researchers have been able to pinpoint that memory deficits in poor readers are not pervasive across the memory system. Instead, primary memory deficits in poor readers seem to be specific to speech tasks (Shankweiler, Liberman, Mark, Fowler, \& Fischer, 1979). One measure that has been used to demonstrate this is a phonological similarity task in which subjects are asked to recall a list of words that share phonological properties (e.g., a rhyming list). The reason this is difficult is because if some of the items in memory start to decompose, such as the initial phoneme, it will be more difficult to guess or differentiate that word from other phonologically similar words. For example, differentiating the letter $\mathrm{C}$ from $\mathrm{D}$ or $\mathrm{E}$ will be harder than differentiating it from $\mathrm{W}$ or $\mathrm{X}$. These phonological similarity effects with lists of similar phonemes are thought to provide evidence of phonological coding and storage in verbal memory measures; i.e., that linguistic information is maintained and organized phonologically. Research has shown that good readers have a pronounced phonological similarity effect where poor readers often have reduced effects (Shankweiler et al., 1979). Less sensitivity to phonological effects has been hypothesized to reflect weaknesses that may be, in part, a reflection of deficits in speech perception (if it is not properly perceived, then it can not be properly rehearsed or represented in working memory). Alternatively, poor readers may also suffer from inherent deficits in storage capacity available for phonological information or from other factors influencing phonological memory such as weak retrieval skills 
There are two ways in which problems in verbal memory may inhibit reading acquisition and reading skills. First, the ability to hold information in working memory is a necessary pre-requisite for comprehension of written material (Cowen, 1996). Shankweiler (1989) also has argued that the challenges poor readers face on comprehension tasks are not caused by gaps in syntax knowledge that interfere with language processing, as many researchers believe. Instead, difficulty comprehending language seems primarily related to problems remembering complex sequences of information. He cites several studies demonstrating that the problems encountered by poor readers in understanding relative clauses, temporal terms, and other examples of complex grammar are actually due to problems they have holding the information in working memory long enough to grasp the intended meaning.

The second way in which verbal memory may inhibit reading is via phonological processing. Shankweiler (1989) proposes that working memory is a skill dependent upon the phonological processing system, and therefore, that phonological processing can also be implicated in the poor comprehension skills of poor readers. As mentioned earlier, phonological processing has been identified as an underlying factor in the deficits of poor readers, but it seems that it also may be the culprit when comprehension of complex linguistic information is required. Some evidence to demonstrate that working memory skills are associated with reading via specific phonological processing skills was gathered by Rapala \& Brady (1990). In their study comparing good and poor third-grade readers, working memory deficits in poor readers significantly corresponded to less accurate phonological processing, and this association was unique to verbal working memory. By studying a cross section of pre-kindergarten, first-grade, and third-grade children to look 
at developmental changes, results indicated that increases in working memory at each grade level were accompanied by more accurate and rapid execution of phonological tasks. This associated development was present even when controlling for age; i.e., as phonological skills develop, so too does verbal working memory performance (or viceversa). In addition, as noted earlier, deficits in nonverbal working memory skills were not found in these children relative to the normal readers. Further, significant correlations were not observed between nonverbal working memory skills and phonological processing.

Therefore, verbal working memory appears to be necessary for reading comprehension and also appears to be strongly associated with phonological processing. Because both of these skills have been shown to be linked with reading abilities in general, and with reading fluency in particular, an examination of the role working memory may play in the development of reading fluency might prove informative.

\section{Oromotor Skills}

There also appears to be a relationship between a child's articulation skills and his or her reading ability. It is important to note that overt or more obvious articulation deficits such as stuttering and lisping are not of concern here. Young children with early speech articulation deficits do not necessarily demonstrate significant difficulties in acquiring reading skill (e.g., Catts, 1991). Rather, it is the underlying skills and abilities necessary for articulation, such as motor planning and quality and retrieval of phonological representations that may be involved in reading development. For example, there is evidence that the oromotor speed and sequencing skills of some children with 
dyslexia are deficient relative to their normal reading peers. Stanovich (1988) showed that poor readers ten-years-old and younger were deficient in the rate at which they repeated simple couplets. Similarly, Wolff, Mitchell, and Ovrut (1990) identified deficits in adolescents and adults with dyslexia when they were required to rapidly repeat sequences of syllables (e.g., pa-ta-ka) to varying beats of a metronome. Furthermore, Catts (1986) noted oromotor accuracy problems based on a significant occurrence of errors when fourteen-year-old, children with reading disabilities were asked to repeat phonologically complex words and phrases (e.g., "aluminum"; "brown and blue plaid pants"). Other evidence for oromotor accuracy problems comes from a study examining performance on a tongue-twister task (e.g., "see-she") and a word pair repetition task (e.g., "car/hat"). Results indicated that the performance of a group of less skilled thirdgrade readers was significantly below that of a group of younger children matched for reading level and a group of children their own age who were good readers (Stone \& Brady, 1995). These findings suggest that differences in oromotor accuracy may be related to specific deficits rather than developmental delay.

Evidence also exists that some poor readers lack an awareness of the position of their articulators such as tongue, teeth, and lips during speech. Montgomery (1981) asked reading-age matched dyslexic and normal readers to produce specific speech sounds or phonemes and to point to the drawing from a set of vocal tract profiles that matched the positions of the oral mechanisms (i.e., tongue, teeth, lips) necessary to produce those phonemes. Although this was a difficult task for all subjects involved, results indicated that the dyslexic subjects had significantly greater difficulty identifying the correct positions of the oral mechanisms. These results suggested that children with reading 
difficulties may not benefit as much from proprioceptive information about the place of their articulators, perhaps limiting information available to them for achieving phoneme awareness and the alphabetic principle.

Currently, there is great debate over whether these oromotor rate and accuracy deficits are primarily reflective of motor skill deficits (Nicholson \& Fawcett, 1990) or phonological core deficits including speech perception and phonological representations (Rapala \& Brady, 1990; Stone \& Brady, 1995), and/or whether articulation rate and skill mediates memory span and memory span deficits (Baddeley, Thomson, \& Buchanan, 1975), which in turn hinders reading performance. Regardless of the answers to these debates, the presence of underlying oromotor and phonological representation difficulties in the reading-disabled population is significant. Furthermore, it seems possible that oromotor skills may be related to reading fluency because they are so closely aligned with skills associated with RSN discussed above. Scarborough and Domgaard (1998) collected evidence suggesting that performance on RSN tasks is only worse in poor readers when a more complex verbal output is required. They measured the rapid serial naming skills of participants using a yes-no response format (e.g., "Is it an H?" and "Is it a lower case c?"), thereby minimizing the usual oromotor and lexical retrieval demands of the task, and found that the association between RSN and reading ability was no longer significant. . Therefore, although the exact nature of the association between articulation and general reading skills is not clear, it is likely that it bears a relationship to reading fluency that would be interesting to explore. 


\section{The Present Study}

To review, the importance of fluent reading skills in the development of reading ability is undeniable. A noteworthy number of readers who manage to acquire the foundation skills for reading encounter later difficulties attaining reading skills that are reasonably rapid and expressive. Lack of reading fluency appears to be associated with problems in reading comprehension, the ultimate goal of the reading process, although the exact nature and degree of this relationship requires further investigation. Lack of fluency also may be associated with interest in and motivation to read, which has consequences for continued practice, print exposure, and the subsequent development of reading and language abilities.

Yet, the constructs related to fluency are poorly understood, both in terms of underlying cognitive and linguistic factors and in terms of reading skill. Prior research has reported a strong link for beginning readers and for older disabled readers between comprehension and the speed of reading (Fuchs et al, 1988) and between reading rate and decoding accuracy (e.g., Faulkner \& Levy, 1999; Tan \& Nicholson, 1997). Not surprisingly, if a reader struggles to identify the words on the page, this limits fluency as well as higher-order reading processes. What is less well explored is the nature of fluency when the reader has adequate decoding skills to read accurately at the word level. As noted earlier, the concept of fluency encompasses rapid, accurate reading with smooth phrasing and good expressive quality. However, there is a need to understand the bases for advanced fluency skills when weak decoding is not an obstacle.

The present study examined the correlates of fluency for third- and fourth-grade children reading at their independent reading level (i.e., when able to read at least $98 \%$ of 
the words accurately and automatically). Focusing on fluency when accuracy was not impeding performance enabled an exploration of the components of fluency (rate, phrasing, expressive quality) both in terms of underlying cognitive predictors and in terms of associated reading skills. Drawing on the literature reviewed earlier, six cognitive and linguistic abilities were assessed: oromotor speed and accuracy, rapid serial naming, verbal working memory, syntax abilities (judgment and correction of sentences), and listening comprehension. In addition, the participants' reading abilities were measured: decoding speed and accuracy on word lists, as well as word recognition and reading comprehension of connected text.

The following specific questions were addressed:

1. Which abilities are the strongest predictors of the different components of reading fluency? That is, which cognitive and linguistic skills contribute the most unique variance to (a) reading rate (b) phrasing, and (c) expressive quality.

2. To what extent is variance in reading comprehension accounted for by each of the different aspects of reading fluency (i.e. rate, phrasing, expression)?

Accordingly, for each element of reading fluency, the following hypotheses regarding the underlying cognitive and linguistic predictors were generated. In addition, predictions were made regarding the relationships among various reading abilities and the contribution to reading comprehension accounted for by the different components of fluent reading skills. 
Regarding the construct of reading rate in particular, it was hypothesized that oromotor speed and accuracy and rapid serial naming would be significant predictors. Performance on independent measures of decoding and word recognition speed also were hypothesized contribute significantly to reading rate. In addition, it was hypothesized that reading rate would, in turn, contribute a significant amount of unique variance to performance in reading comprehension.

Hypotheses were also generated concerning the underlying skills necessary for good prosodic quality in oral reading. The two primary components of prosody, expressiveness and phrasing, were examined separately and jointly, and it was predicted that working memory, syntax skills, and listening comprehension would contribute significantly to the variance in both. It was also hypothesized that word identification and decoding speed, and independent reading level would be related to prosodic quality. Finally, it also was predicted that a significant amount of variance in reading comprehension would be accounted for by both features of prosody. 


\section{Chapter II}

\section{METHOD}

\section{Participants}

Third- and fourth-grade students enrolled in a public elementary school in Westport, Connecticut were solicited for participation in this study ${ }^{1}$. This town is a suburban, primarily Caucasian community, with middle to upper-income families. Out of 210 students given permission forms (see appendix A), a total of 98 students returned them with parental consent. ${ }^{2}$ Third- and fourth-grade students were chosen because they were likely to be at the appropriate reading level for inclusion in the study (i.e., ability to read independently at a second-, third-, fourth-, or fifth-grade level). Fifteen of those students did not meet the reading ability level criterion, and their data, therefore, were not included in the final analysis. As a result, the final sample size for this study was $\mathrm{N}=83$. Descriptive information about this sample is provided in Table 1.

\footnotetext{
${ }^{1}$ A total of 210 students were solicited based, in part, on consultation with a statistician who completed a power analysis for multiple regression, setting the goal for power at .80, using a two-tailed alpha $=.05$, a range of effect sizes and eight predictor variables. Results of this preliminary analysis indicated that between 60 and 250 subjects would be necessary. Because the expected effect size was not known, and up to nine predictor variables actually would be used, it was estimated that if the effect size fell between .20 and .10, approximately 60 to 125 subjects were needed.

${ }^{2}$ Relative to the school population as a whole, proportionately fewer special education students were granted parental permission to participate. However, this did not pose a problem in terms of the representativeness of the sample because the more severely disabled students would not have been likely to meet reading ability level criteria to participate. With respect to the regular education students, no clear pattern regarding the type of student allowed to participate emerged. In talking to parents, it seemed that those who had children who were good readers were eager to allow participation knowing that their child would experience success. In addition, many parents of children who were poor readers were eager to have them participate as a way of helping to contribute to our understanding of the nature of reading difficulties. Therefore, the final sample was considered representative of the school population as a whole.
} 
It should be noted that children who were in a special education program were allowed to participate in this study, providing they met the above-mentioned reading level criterion. Eight special education students from the school received parental permission and participated in the screening phase of this study. Four were classified as Learning Disabled, two as Speech and Language Impaired, one as Hearing Impaired, and one as Autistic. Out of this group of eight special education children, two were able to read at the specified level and were designated as appropriate for inclusion in the final data analysis. One of these students is classified as Learning Disabled (nonverbal learning disability), and the other is identified as Speech and Language Impaired. Both were able to read independently at a fifth-grade level, the highest level used in this study.

Table 1

Demographic Characteristics of Participants who met Study Inclusion Criteria

\begin{tabular}{lcccc} 
Grade & $\mathrm{N}$ & Males & Females & \multicolumn{1}{c}{ Age* } \\
Third & 37 & 15 & 20 & M (SD) \\
Fourth & 46 & 22 & 26 & $9.08(.31)$ \\
Total & 83 & 37 & 46 & $9.03(.34)$ \\
\hline
\end{tabular}

* age is reported in years

\section{Materials}

\section{Word Lists}

To estimate the level at which each participant could read successfully without assistance, all students were asked to read lists of words from the Qualitative Reading 
Inventory - 3 (QRI-3; Leslie \& Caldwell, 2001). This is a non-standardized, criterion referenced instrument designed for individual administration.

The word lists that the participants read each contained twenty words selected from QRI narrative passages described below. Each list was at a second-, third-, fourth-, or fifth-grade readability level. The participants were initially given the word list that corresponded to his or her grade level and asked to pronounce the words while the examiner recorded the responses. When the student was finished reading the list, the examiner determined whether the participant was able to read that list at an independent reading level.

Determination of an independent reading level was based on two factors: a) if ninety percent of the words (i.e., eighteen) were read without errors and b) if the words correctly read were also read automatically (i.e., within one second). If these criteria were not met, then the student did not demonstrate independent reading ability at that grade level, and the next lowest level word list was administered. Conversely, if the participant met or exceeded those criteria, the next highest level word list was administered. In either case, the same scoring criteria (i.e., recording errors and speed) were used until the highest level at which a participant was able to read was identified.

\section{Oral reading passage}

In order to determine each participants' ability to read text aloud fluently, narrative passages from the QRI were administered and scored on four dimensions: reading rate, reading accuracy, phrasing ability, and quality of expression. Second-, third-, fourth-, and/or fifth-grade passages were administered to each student based on the assessed independent word reading level attained for that child. For example, a 
participant who was estimated to be reading independently at a third-grade level, based on the word lists, was initially administered a third-grade narrative passage ${ }^{3}$.

If a child was unable to read the lowest level word list (i.e., the second-grade list) independently, he or she was still administered the second-grade passage to read aloud. Even if the word lists yielded lower than second-grade level reading ability, it seemed valuable to ensure that the individual's passage reading skill might not exceed his or her isolated word reading skill. If a participant was able to read the second-grade passage independently, regardless of his or her word list reading accuracy and automaticity, that data was included in the study.

The following directions were given to each participant as the passages were administered: "Read this story about aloud in your best 'read-aloud' voice. Make sure your voice is loud and clear so you can be heard on the tape. When you are finished I will ask you a few questions about what you read. Please start when I say 'go'.” While the participant read, the examiner recorded all reading errors on a worksheet and determined the time it took to read the passage with the use of a stopwatch.

\footnotetext{
${ }^{3}$ The examiners' manual of the QRI explains that several readability formulae were used to determine the readability level (i.e., grade level estimates) of each passage. Secondand third-grade level passages were analyzed using the Harris-Jacobsen formula, the Wheeler and Smith Formula, The Spache Readability Formula, and the Fry Readability Graph. The readability levels of the fourth- and fifth-grade passages were determined using the Harris-Jacobsen and the Fry Readability Graph, as well as the Dale-Chall formula (1948). Each of these methods employs a variety of different strategies to derive readability estimates. An examination of the difficulty of the vocabulary words based on word frequency and/or a tabulation of the number of syllables are two procedures.

Another is to determine the average number of syllables per word, the average number of syllables per sentence, and/or to determine the average sentence length per passage. Using these different strategies, the readability of each passage was ultimately determined when three out of four formulae yielded the same results, in the case of the second- and third-grade passages. For the fourth- and fifth-grade passages, two out of three formulae needed to yield the same results to obtain what the authors considered to be reliable readability estimates.
} 
Independent Reading Level Estimates When the participant was finished reading, the examiner determined whether he or she was able to read the passage at an independent level. In the case of passage reading, which is different from word list reading, an independent level was considered to be the level at which the child was able to read ninety-eight percent or more of the passage without errors. If a child was unable to read the first passage that was administered to him or her at an independent level, then the passage just below that level was administered following the same procedures and directions. This process continued until the participant was able to read a passage at an independent level.

Reading Accuracy To determine how accurately the passage was read, all decoding errors were marked and tallied while the participants read the passage. Additionally, each passage reading was tape-recorded, reviewed, and scored at a later date to verify that all errors were originally identified and tallied correctly. Four types of decoding errors were identified, and each was counted as a single error. Specifically, when a word was read incorrectly, it was scored as a substitution. When a word was not read at all, it was scored as an omission. An insertion error was recorded when the student read an additional word that was not actually in the passage. Lastly, when the student transposed two words or phrases in the passage, it was tallied as a reversal error. Words that were self-corrected, meaning that the child started to read the word incorrectly but corrected him or herself, were not counted as reading errors, although these reformulations were noted when determining the child's ability to read with appropriate expression and phrasing (see below). The QRI-3 manual provides an interrater reliability estimate based on an examination of scores obtained by three separate 
examiners. Using the above scoring criteria, reliability was in excess of .98 for the passages used in this study.

Reading Rate After each participant finished reading the passage, tabulation of his or her reading rate was made. Reading rate was based on the number of syllables in the passage multiplied by sixty and divided by the number of seconds that elapsed from the time the examiner said "go" until the child finished pronouncing the last word in the text. This calculation resulted in a syllables-per-second (SPS) score for each child on the passage he or she read. A decision to use SPS rather than the number of whole words read per second was made in an effort to compensate for variation in word length and complexity that occurs among passages at different reading levels. Overall, the higher level passages contained more long words with a greater number of syllables than the lower level passages. Therefore, had a words-per-second score been used, it may have resulted in spuriously high reading rate scores for those students who read lower level passages, relative to those who read higher level passages.

Reading Comprehension In order to assess the amount of information understood by each participant as he or she read the passage, eight comprehension questions were administered orally. The questions were taken from the QRI-3 manual. Five questions targeted the ability to understand details from the passage that were explicitly stated, and three targeted inferential comprehension. Participants were asked to provide their answers orally, and the examiner recorded his or her responses on an answer sheet. Occasionally, it was not immediately clear whether a participant's answer to a question was correct. These items were queried, as directed by the QRI-3 manual, to obtain clearer responses when possible. If the examiner still was uncertain, at a point after 
administration, she conferred with one of the other examiners until both agreed on the accuracy of the response. The total raw score for passage comprehension was the percentage of comprehension questions answered correctly.

According to information provided in the QRI-3 manual, analysis of variance of the standard error of measurement (SEM) scores was used to estimate the internal consistency of the comprehension questions. This procedure was chosen because traditional correlation methods are not as appropriate for criterion-referenced measures due to a reduced amount of variability in subjects' performance. The standard errors of measurement for comprehension questions of passages that were administered in this study ranged from .13 to .17 .

Prosodic Quality In addition to determining each participant's oral reading rate, accuracy, and comprehension, an estimate of the prosodic quality with which the passages were read was also calculated. The author of this study judged the taperecorded oral readings of each reader along the Prosodic Quality Scale for Reading (PQSR). The PQSR was originally derived from The Fluency Scale (Allington, 1983). Changes were made to The Fluency Scale based on experience gained during a pilot phase of this study, and in order to adapt the scale to the materials used in this study. This measure had two subscales: one evaluated the student's ability to read in appropriate phrases and the other judged expressive quality of the oral reading. Criteria from the scale can be found in Table 2 .

Each sentence and/or component of an extended compound sentence was marked within each of the different grade-level passages. For every participant, all of the sentence units were rated along a four-point scale for phrasing ability and rated 
Table 2

Prosodic Quality Scale for Reading

Expression

primarily monotone 1

minimal expression 2

moderate expression 3

adult-like expression 4
Phrasing

primarily word-by-word reading 1

minimal phrasing 2

moderate phrasing 3

adult-like phrasing 4

again along a different four-point scale for quality of expression, based on the criteria listed in Table 2. Then, the separate ratings given for each individual sentence or sentence unit for expression were added together to obtain a total expression raw score.

Next, raw scores were converted to percentage scores, by dividing them by the total possible points one could have earned. The same procedure was followed for the individual phrasing ratings on each of the passages; all of the points earned were added together to obtain a phrasing raw score, and that raw score was then divided by the total possible phrasing points one could have earned to arrive at a phrasing percentage score. Finally, the expression and phrasing raw scores were added together to yield a total prosodic quality raw score for each participant. That raw score was then divided by the total possible points one could have earned for both phrasing and expression to obtain an overall prosodic quality percentage score. Note that raw scores were converted to percentages to account for variance in passage length. Using percentages allowed for a more standardized score for individuals who read different passages and were the scores used in the final analyses.

Several special circumstances arose during the rating of the passages. In some cases, participants read two sentences without pausing appropriately for the period in 
between them. When this occurred, both sentences involved were penalized on the phrasing component of the scale by one point. Therefore, for both sentences, the highest possible phrasing score that could have been earned began as a three rather than a four.

In other cases, a sentence or single word within a sentence was read incorrectly, and then either that word or the entire sentence was re-read in an effort to self-correct the error. When these self-corrections or reformulations occurred, the highest possible phrasing score the participant could receive for that sentence was, again, a score of three rather than four. Conversely, when self-corrections occurred (whether it was a single word or a complete phrase or sentence), only the second attempt was scored for expression. Thus, expression scores were not penalized when the participant made an error that they attempted to correct. This scoring strategy was chosen because it was difficult to determine the type and quality of expression intended on words or sentences that were initially decoded in error.

Finally, in some cases, a participant may have skipped an entire line within a passage. This occurred only twice, but when it did, the average of all ratings the participant earned for that passage was applied to the skipped sentence or sentences in that line and included in the tabulation of the raw score.

All of the participants' oral readings were rated by the author of this study. Two strategies were employed in an attempt to control for possible error or bias in the use of this scale. First, before attempting to rate all of the participants' passages, three cases were randomly chosen and their oral readings were judged independently by the author of this study as well as the other graduate student examiner. Then, both examiners compared each of their ratings, and any differences that arose were discussed and 
questioned until there was complete agreement. The purpose of this preliminary strategy was to enable both raters to develop a sense of the different values of the points within the PQSR, and how the range of ratings should be applied to the variable quality of the participants' phrasing and expression.

An estimate of inter-rater reliability for the scale was obtained. Approximately one-third of the cases $(\mathrm{N}=27)$ were randomly selected and scored by both the author and the second examiner independently. The phrasing, expression, and total prosodic quality ratings for those cases were entered into a statistical program and analyzed for agreement using a Pearson Correlation. The results of that analysis yielded strong inter-rater reliability estimates for all three components of the scale. The correlation for the phrasing ratings was $r=.93(p<.01)$. The correlation for the expression ratings was $r=$ $.96(p<.01)$, and the correlation for the total prosodic quality ratings was $r=.96(p<$ $.01)$.

\section{Tongue-Twister Tasks}

A phrase repetition task was administered to each participant in order to assess oromotor speed and oromotor accuracy. This task was modeled after one described by Catts (1989). Subjects were asked to repeat, as quickly as possible, two and three-word speech sequences. Half of the items contained relatively simple phonological patterns and the other half were more phonologically complex (see Appendix B). The number of times each of the utterances was repeated before subjects were told to stop varied randomly from ten to fifteen. However, only the first ten repetitions were scored. This procedure was followed to minimize the chance that participants might alter their speech rate on the last few items if fixed-length repetitions of ten items were required each time. 
During test administration, the examiner recorded the accuracy with which items were repeated on a worksheet, and used a stopwatch to judge the time it took the participants to say each trial of ten items. At a later point in time, both the accuracy and speed judgments were verified by one of the other examiners who listened to the taperecordings of each participants' performance.

Oromotor Speed scores were based on the total time taken to utter a continuous sequence of eight simple tongue-twister items correctly. To avoid accuracy-speed tradeoffs, if an item was not accurately repeated eight times in a row, that trial was not counted into the final tally for speed performance. The participant's total time was divided by the total number of syllables uttered correctly within each item to achieve a syllable per second score. This is the score that was used in the final analyses. Internal consistency estimates for this measure were .90 (Cronbach's Alpha).

In order to arrive at an Oromotor Accuracy score, errors in the way that both simple and complex items were repeated were tallied. Four types of errors were marked: (1) when one sound became like a neighboring sound in position or type of articulation (e.g., "blue blush" or "brue brush"); (2) when a different phoneme was substituted (e.g. "bruch" for "brush"); (3) when a word was repeated incorrectly (e.g., "weak ditch" for "weak wrist"): and/or (4) if the person stuttered (e.g., "f-f-five fruit flies" for "five fruit flies"). All of these mistakes, on both simple and complex tongue twister items, were added together to get a total error score for oromotor accuracy. The estimate of internal consistency for this measure was .72 (Cronbach's Alpha). 


\section{Word recognition speed}

In order to determine the speed and accuracy with which the participants could read a list of real printed words, the Sight Word Efficiency subtest of the Test of Word Reading Efficiency (TOWRE; Torgesen, Wagner, \& Rashotte, 1999) was administered. This test requires a child to read as many words as possible within a 45 -second time limit. Only the words read correctly were included in the tabulation of raw scores, which were then converted to standard scores based on age-norm data provided in the examiner's manual. According to information provided in the manual, these tasks have been found to correlate highly with other well-known power tests of word recognition ( $r=.86$ to .94 ), yet the administration time is significantly reduced. In addition, test-retest reliability estimates for age groups comparable to the age of participants in this study ranges from $r$ $=.84$ to .97 .

\section{Decoding Speed}

The speed with which the participants could read a list of unfamiliar words was assessed using the Phonemic Decoding Efficiency subtest from the TOWRE (Torgesen et. al, 1999). This task required the child to read as many pseudowords as possible within a 45-second time limit. Only pseudowords read correctly were included in the tabulation of scores. Again, raw scores were converted to standard scores and percentiles based on age-norm data provided in the test manual. As with the Sight Word Efficiency subtest, this subtest also correlates highly with popular power tests of word attack skills $(r=.87$ to .91), yet the administration time is shorter. Test-retest reliability for age groups comparable to the age of participant's in this study ranges from $r=.89$ to .90 , according to the TOWRE examiner's manual. 


\section{Listening Comprehension}

Each participant's ability to comprehend oral language was measured with the Oral Comprehension subtest from the Woodcock Johnson Psychoeducational Battery Third Edition, Tests of Academic Achievement (McGrew \& Woodcock, 2001). This is a cloze procedure task that requires the person being evaluated to listen to a tape-recorded reading of multiple sentences and brief passages. Tape recorders with dual headphones were used to administer the pre-recorded stimuli, so that both the examiner and the participant could listen to the items simultaneously. As the participant answered each item, the examiner recorded his or her responses on the answer sheet. Unclear responses were queried as need, as indicated in the test-administration instructions for this subtest. All correct responses were tallied to obtain a raw score. These raw scores were converted to standard scores based on age-norm data provided in the test manual.

According to the test manual, test-retest reliabilities for this measure range from $\mathbf{r}$ $=.74$ to .82 , for age groups comparable to those used in the present study sample. Internal consistency using split-half reliability estimates (with Spearman-Brown correction formula), again for comparable age groups, ranged from $r=.78-.83$. Evidence for the validity of this measure is based partially on correlations between the Listening Comprehension composite of the Woodcock Johnson-III, which is comprised of this Oral Comprehension subtest, and the Listening Comprehension Subtest of the Wechsler Individualized Achievement Test $(\mathrm{r}=.55)$. The latter measure is different than the Oral Comprehension test used in this study, as it requires the child to listen to several passages and answer 2-3 questions about each. 


\section{Digit Span Backwards Task}

Each participant was asked to listen to a series of digits and repeat them in reverse order to obtain an estimate of working memory skills. Items were modeled after those in the Wechsler Intelligence Scale for Children - Third Edition (Wechsler, 1995). The first three trials required the participant to listen to the examiner utter two numbers, at a rate of one number per second. After each sequence, the child was asked to repeat those digits backwards. The second three trials required the same procedures, but the number of digits increased by one. On all items that followed, in a cluster of three, the number of digits the participant was required to listen to and repeat backwards increased by one. Test administration was discontinued when a participant made an error on all three items within a cluster. The total number of items accurately repeated backwards was tallied and used as the raw score to be included in the final analyses.

The primary difference between this task and the one after which it was modeled is that this task only requires the participant to repeat digits in backwards order. The original task published in the WISC-III, requires the child to repeat a set of digits as presented (i.e., forwards) first, and on a second part of the task, to repeat digits backwards. The reason only the backwards span task was used here is that accurate performance on backwards and forward span tasks is thought to require different cognitive processes (Sattler, 1988; Lezak, 1995). Therefore, reliability estimates from the original task and this one should not be strictly comparable. Bearing this in mind, internal consistency estimates for the backward and forward span tasks published in the original test manual based on Split-Half correlations (using Spearman-Brown correction 
procedures) ranged from $r=.82$ to .84 for children of the same age as those who participated in this study.

\section{Syntax Correction}

To assess each participant's level of Syntax Awareness, the Grammatic Comprehension subtest from the Test of Language Development - Intermediate, Third Edition (TOLD-3; Hammill \& Newcomer, 1997) was given. This test required subjects to listen to a sentence presented by the examiner and determine whether it was grammatically accurate. The number of items answered correctly was tallied by the examiner during administration to obtain a raw score. That raw score was then converted to a standard score using age-norm data provided in the test manual. This standard score was the one that was used in the final analyses. Internal consistency estimates for this measure, as published in the test manual, range from $r=.96$ to .97 for age groups comparable to those who participated in this study. In addition, test-retest reliabilities for all age groups was $\mathrm{r}=.91$.

At the end of this task, in addition to the standardized procedures specified by the test developers, the examiners re-administered all of the items that the participant had identified as incorrect, and the participant was asked to correct these items. If he or she was able to recognize that, for example, "The boy are playing." was a grammatically incorrect sentence, it was read to them again, and they were asked to tell how the sentence could be altered to be made grammatically correct. This procedure was included because previous research has suggested that a child's ability to identify inaccuracies in syntax is not as strongly related to reading ability as is the ability to correct the error (Fowler, 1988). 
Performance on this secondary task was based on the number of items that were correctly identified as incorrect and then changed into the correct grammatical or syntactical form. A percentage of items accurately identified as incorrect, and then accurately changed to a correct syntactical form, is the score that was used in the final analysis.

\section{$\underline{\text { Rapid Serial Naming }}$}

A rapid serial naming task was administered to each participant to assess speed of lexical retrieval and motor planning. Specifically, the Rapid Letter Naming task from the Comprehensive Test of Phonological Processing (CTOPP; Wagner, Torgesen, \& Rashotte, 1999) was used. This task requires the participant to pronounce, as quickly as possible, the names of six different letters presented in a $9 \times 4$ matrix. The letters are arranged randomly and occur no more than twice in each row. The set of letters is shown to participants in isolation first to establish familiarity with the items. Then the examiner asks each participant to name the letters in the matrix as quickly as possible. In this study, the examiner judged the time it took to name all letters in the array with the use of a stopwatch. Items were marked incorrect if the participant skipped a letter or gave the wrong name. A separate score for errors and self-corrections was not calculated, but did contribute to longer naming times for the participants. The number of seconds it took to complete the array was converted to a standard score based on the age-norm sample for this measure.

According to the test manual, internal consistency estimates for this measure were derived by comparing performance on alternate forms of this task. This was done because internal consistency based on inter-item correlations is not applicable on timed 
measures such as this one. Instead, alternate form reliability coefficients are provided, and ranged from $\mathrm{r}=.73$ to .86 for age groups comparable to the participants in this study. In addition, test-retest reliability for this measure across all age groups was $r=.97$.

\section{Examiners}

Three examiners were involved in the data collection process. One was this author, who is a graduate student with extensive experience in childhood assessment procedures in literacy and other areas. The second was also a graduate student who had taken courses in childhood assessment and reading research, and has completed approximately 400 hours of supervised assessment experience. The third was an undergraduate recruited from a special education teacher training program. She had taken one course in assessment principles and procedures, but did not have any direct testing experience prior to this study. Each examiner was required to review both the methods section of the proposal for this dissertation and the manuals that were available for the standardized measures that were administered. The undergraduate examiner also was required to observe the administration of the battery by each of the other two examiners. In addition, she administered the battery to each of the examiners and an additional adult volunteer to practice the procedures and review any potential problems or questions before collecting data for the study.

\section{General Test Administration Procedures:}

Participants were recruited through letters describing the study that were mailed home to parents. This letter was written by the school principal, and it outlined the 
benefits for the school that this study would afford (see Appendix C). Also sent home was a parental permission slip that contained a detailed description of the study. ${ }^{4}$ To increase the likelihood of achieving the desired number of participants, all letters and permission forms were sent home with a stamped and self-addressed envelope to use to return the forms. In addition, parents were told that a written summary of their child's performance on the different reading tasks would be made available for them to review if desired.

Prior to the start of data collection, the three examiners toured the school and introduced themselves in each of the third- and fourth-grade classrooms. The children were told that they were being asked to participate in a research project about reading, and the general procedures of the study were described to them. All students were told that their parents would receive in the mail information about the study, and they were encouraged to have their parents complete and return the forms. It was highlighted that none of the students was required to participate, and their grades in school would not be affected if they chose to abstain, even if their parents had given their permission. Finally, the students were told that if they did participate, they would receive either a gift certificate for an ice-cream cone at a local store or a designer pencil to thank them for their help.

The data collection phase of this study began in the beginning of May and lasted through the end of the school year (i.e., June $20^{\text {th }}$ ). All participants were seen individually for two separate testing sessions, each lasting approximately 30-40 minutes. Each was taken from his or her classroom at a time that had been pre-approved by the child's

\footnotetext{
${ }^{4}$ These letters were reviewed by the Institutional Review Board at the University of Rhode Island, prior to the mailing.
} 
teacher. In addition, some children were scheduled to be tested during times that also were approved by the participants' parents because those parents had concerns about their child missing certain classroom lessons. In approximately twelve cases, this included being tested after school rather than during the school day.

Most of the testing took place in a small classroom within the school that is used for individualized, pull-out teaching. This room was quiet, free from distractions, and in proximity to the classrooms from which the participants were taken. However, an additional room was also needed because, on many occasions, two examiners were working with the participants simultaneously. This second room was smaller and was often used as a time-out room for the self-contained special education students in the district. This room was farther away from the participants' classrooms.

On the first day of testing, each student was reminded of the purposes and procedures that would be used in the study. They were informed that their parents would receive some information about how they did on the various reading tasks, but that their performance would have no impact on their grades in school. If they agreed to participate, they were asked to sign a letter of assent (see Appendix D) verifying their willing participation. All children who had been granted parental permission gave their assent.

The following recording equipment was used to record all testing sessions: Marantz Stereo Cassette Recorders - model number PMD 430, Maxell XIII 90-minute audio cassettes, and Radioshack Cardioid Dynamic Microphones. Before each testing session, this equipment was checked to ensure that it was working properly, and to allow the participants an opportunity to examine it. The participants were then told that the 
entire testing session would be recorded except for the listening comprehension task described earlier.

The first five tasks discussed earlier were administered on the first day of testing. This included QRI word lists, QRI passages, Tongue Twister Tasks, Word Recognition Speed, and Decoding Speed. The remaining four tasks were administered on the second day (i.e., Listening Comprehension, Digit Span Backwards, Syntax Judgment and Correction, and Rapid Serial Naming). Standardized instructions were used for explaining all tasks. In other words, exactly the same directions were read by all three examiners to each of the participants. Responses were recorded on a protocol packet that identified each participant by an identification number only. In other words, the participants' names were not recorded on the packet itself in an effort to maintain confidentiality. At the completion of the first testing session, the child was given either a lollipop or a sticker. The majority of children chose the lollipop. After the second day of testing the participants were offered a pencil or a gift certificate for an ice cream cone. In this case, the majority of participants chose the gift certificate. 
Chapter III

\section{RESULTS}

General Plan of Analysis

Descriptive statistics were conducted first, and the normality of the distributions was assessed. Pearson correlations were conducted to evaluate the relationships among the data set collectively, and then partial correlations were conducted to evaluate the data set while controlling for independent reading level. Two Factor Analyses were conducted in order to determine the constructs underlying the passage reading measures independently, and to determine the underlying constructs of the other cognitive and linguistic measures, and the entire data set as a whole. Next, Hierarchical Multiple Regressions were conducted to ascertain the amount of variance accounted for in the fluency variables (i.e., rate, phrasing, expression) by the linguistic and cognitive measures. Finally, three separate sets of Chi Square analyses were conducted to look for associations between reading comprehension and reading rate, phrasing, and expression.

\section{Descriptive Statistics}

The descriptive statistics of the performance of all 83 children who met selection criteria were evaluated as a whole for the presence of missing data and to assess normality. The significance of skewness and kurtosis of all variables and the differences between medians and means, and relative size of the standard deviations, were evaluated. In addition, histograms and probability plots of the frequency distributions were also reviewed. 
An examination for the presence of missing data indicated that one participant was unable to complete the Rapid Serial Naming task following standardized procedures. This participant was far-sighted, did not have glasses, and made too many errors on this task for her score to be calculated using the normative data provided in the test manual. Performance for this subject on all other measures, including reading tasks, was approximately at or above the means or medians for the sample and was always within one standard deviation of the sample mean. Several options were considered for handling this missing data point. Extrapolating a score for this participant from the mean of the sample as a whole on the Rapid serial naming measure seemed the most appropriate procedure.

In terms of normality for the passage reading measures, only rate was normally distributed. Accuracy, phrasing, expression, prosody, and comprehension were nonnormal (see Appendix E). Due to the design of the study, the distribution of accuracy performance was expected to be non-normal. Because children were asked to read at his or her independent reading level, little variability in reading accuracy should have been obtained. Consequently, there was no intention to incorporate this variable into any analysis, and the lack of normality posed no problem.

For phrasing, expression, and prosody, the variables were negatively skewed. Exponential transformations (base 1.025) were effective in normalizing these variables. Other analyses (i.e., correlations, factor analyses, regressions) were run with variables in both their raw form and in their transformed form. In all cases, the transformed variables yielded stronger linear relationships with expected measures than the raw variables did. 
All analyses reported with these variables used the transformed scores for the measures of phrasing, expression, and prosody.

Correspondingly, several transformations were attempted on the reading comprehension variable. It was possible to obtain a more normal distribution with an arcsine transformation, and the transformed variable did correlate significantly with listening comprehension $(r=.23, p<.04)$. However, the linear relationship with the transformed variable and other relevant variables was not improved. Furthermore, other preliminary analyses were conducted with the arcsine transformation of comprehension (i.e., Multiple Regressions) and no statistically significant regression model was obtained. As a result, non-parametric statistics were used to analyze associations between comprehension and other variables.

Normality of the cognitive and linguistic variables was assessed in a similar manner. All but the syntax correction was normally distributed (see Appendix E). An exponential transformation (base 1.025) was most effective in correcting for normality with this variable, though the final result was still negatively skewed. For that reason, and because this variable did not correlate strongly with most other measures, the syntax correction measure was eliminated from further analyses. Descriptive statistics for all variables are summarized in Table 3.

\section{Pearson Correlations}

In order to evaluate the way in which various measures used in this study relate to each other, a correlational analysis was completed (see Appendix F). This information was used for two purposes: (1) to examine the relationships among variables measured in 
Table 3

Descriptive Statistics for Passage Reading, Cognitive, and Linguistic Measures

\begin{tabular}{lcrr} 
Passage Reading & Mean (SD) & Median & Range \\
\cline { 2 - 4 } Measures & & & \\
Accuracy & $98.58(0.65)$ & 98.48 & $98.00-100.00$ \\
Rate (sps) & $3.20(0.61)$ & 3.32 & $1.75-4.55$ \\
Phrasing* & $8.11(1.84)$ & 8.57 & $3.11-10.70$ \\
Expression* & $9.28(2.14)$ & 9.70 & $3.44-11.81$ \\
Prosody* & $8.62(1.80)$ & 9.00 & $3.70-10.97$ \\
Comprehension & $83.17(14.14)$ & 88.00 & $38.00-100.00$ \\
& & & \\
& & & \\
Linguistic \& & Mean (SD) & Median & Range \\
Cognitive Measures & & & \\
Word Recognition Speed & $112.29(09.81)$ & 113.00 & $87.00-133.00$ \\
Decoding Speed & $109.75(12.66)$ & 109.00 & $87.00-139.00$ \\
Oromotor Speed (sps)** & $2.99(00.42)$ & 2.96 & $2.24-4.45$ \\
Oromotor Accuracy** & $38.07(10.10)$ & 26.00 & $8.00-61.00$ \\
Rapid Serial Naming & $11.30(02.17)$ & 11.00 & $7.00-18.00$ \\
Working Memory** & $8.46(02.65)$ & 8.00 & $3.00-17.00$ \\
Listening Comprehension & $116.39(08.59)$ & 116.00 & $95.00-136.00$ \\
Syntax Judgment & $12.77(02.34)$ & 12.00 & $8.00-19.00$ \\
Syntax Correction** & $107.40(22.21)$ & 106.35 & $40.00-131.00$ \\
* transformed variables. ** non-standardized measures created for the purposes of this \\
study.
\end{tabular}

this study, and (2) to preliminarily assess the occurrence of multicollinearity among variables.

The results initially were examined to get a broad overview of the relationships between various measures. Of particular interest were several bivariate relationships between variables measuring similar constructs.

First, only a moderate correlation was observed between phrasing ability and quality of reading expression $(\mathrm{r}=.59, \mathrm{p}<.00)$. This is noteworthy because it indicated that the two components assessed using the PQSR do share some variance, but that evaluating each separately may still be worthwhile. All subsequent analyses utilized 
these two variables, phrasing and expression, independently rather than using the combined variable of prosody.

Oromotor speed and oromotor accuracy were not significantly correlated $(\mathrm{r}=.11$, $\mathrm{p}<.32$ ), which was unexpected given that they were measured on the same task and were thought to tap similar skills. Furthermore, strong relationships were found with oromotor accuracy and other variables, more so than oromotor speed (with the exception of rapid serial naming), suggesting that accuracy is more highly associated with reading and reading-related skills. In particular, oromotor accuracy was highly correlated with several reading variables including expression and phrasing $(r=-.36, p<.00 ; r=-.45, p$ $<.000$ respectively), reading rate $(\mathrm{r}=-.35, \mathrm{p}<.00)$, word recognition and decoding speed $(\mathrm{r}=-.30, \mathrm{p}<.01 ; \mathrm{r}=-.46, \mathrm{p}<.00$ respectively $)$.

Another important issue to note is that reading comprehension in the raw form did not correlate highly with any measures. An arcsine transformation changed the variable enough that a significant correlation was obtained with the listening comprehension measure, but not with other measures. The fact that reading comprehension, transformed or untransformed, bore no significant linear relationships to any measure other than listening comprehension substantiated the presence of problems with this variable noted earlier.

Finally, independent reading level was significantly related to a number of skills measured. Reading level was moderately correlated with the passage reading measures including reading rate $(\mathrm{r}=.51, \mathrm{p}<.00)$, phrasing $(\mathrm{r}=.55, \mathrm{p}<.00)$ and expression $(\mathrm{r}=.54$, $\mathrm{p}<.00$ ). In addition, reading level was significantly correlated with all other cognitive and linguistic measures except working memory. Age and gender effects were also 
evident with some measures. Not unexpectedly, age was significantly associated with reading level, phrasing, expression, prosody. Gender was significantly associated with reading accuracy, expression, and listening comprehension, with girls tending to perform at higher levels.

The correlational analysis was also reviewed to determine which measures were most strongly related to the designated dependent variables to be used in the regression analyses (i.e., rate, phrasing, expression). With regard to reading rate, significant correlations were obtained with all of the other passage reading variables including reading accuracy $(\mathrm{r}=.27, \mathrm{p}<.01)$, phrasing $(\mathrm{r}=.75, \mathrm{p}<.00)$, and expression $(\mathrm{r}=.54, \mathrm{p}<$ .00 ). Furthermore, numerous correlations were obtained between reading rate and the other cognitive and linguistic variables, particularly those measuring word level reading skills and verbal speed. Rate was significantly correlated with word recognition speed (r $=.68, \mathrm{p}<.00)$, with decoding speed $(\mathrm{r}=.58, \mathrm{p}<.00)$, with oromotor accuracy $(\mathrm{r}=-.35, \mathrm{p}$ $<.00)$ and rapid serial naming $(\mathrm{r}=.39, \mathrm{p}<.00)$.

An evaluation of the variables that correlated most highly with phrasing indicates significant relationships with rate and expression, two of the other passage reading variables. Like reading rate, phrasing was significantly correlated with word level reading skills (word recognition speed $\mathrm{r}=.56, \mathrm{p}<.00$; decoding speed $\mathrm{r}=.55, \mathrm{p}<.00$ ), and verbal processing speed measures (oromotor accuracy as reported earlier; rapid serial naming $\mathrm{r}=.29, \mathrm{p}<.01$ ). In addition, phrasing was significantly associated with syntax judgment $(\mathrm{r}=.25, \mathrm{p}<.02)$. These results suggest that phrasing is a skill that is related to word level and speed skills, but also with abilities above the level of the word, such as those tapping syntax. 
Finally, ratings of expression were also significantly correlated with other passage reading variables, including reading rate, and phrasing, and the results essentially parallel those found for phrasing ability. However, unlike phrasing, significant associations between expression and syntax judgment were not obtained $(\mathrm{r}=.09, \mathrm{p}<.42)$. Overall, these results indicated, for the 83 subjects in this study, quality of verbal expression while reading aloud is significantly related to several of the verbal processing speed and reading skills, but not higher level language processing.

An additional evaluation of bivariate relationships was carried out by evaluating the partial correlation coefficients, controlling for independent reading level (see appendix G). Overall, the strength of most relationships diminished somewhat with this method. However, there were interesting exceptions. First, the correlation between reading comprehension and listening comprehension improved and was significant $(\mathrm{r}=$ $.24, \mathrm{p}<.03$ ). Additionally, the correlation between oromotor accuracy and oromotor speed increased and was significant $(\mathrm{r}=.29, \mathrm{p}<.01)$.

In addition, correlational matrices were created by splitting the entire data set according to independent reading level. This showed some interesting changes in the correlational patterns not tapped by the bivariate procedure. For example, at the second grade independent reading level significant correlations were obtained between reading comprehension and the phrasing and expression variables, but not at the other three levels. Furthermore, phrasing and expression were not significantly correlated for those participants reading at a second grade independent reading level, but the correlations between these two variables were significant at all other levels. Because the sample sizes when examining these groups independently were small, particularly at the second and 
fourth grade levels, these results are not as reliable as when examining the entire data set as a whole. For that reason, they have not been reported here, and must be interpreted with caution.

\section{Factor Analyses}

In order to obtain a summary of the passage reading variables and the remaining cognitive and linguistic variables, two separate factor analyses were performed. The first evaluated the variance among the passage reading variables alone, and helped to determine the relationships among specific fluency variables, per se. Two factors were extracted (see Table 4) with strong factor loadings.

Table 4

Factor Loadings for Passage Reading Variables

\begin{tabular}{lcc} 
& Factor 1 & Factor 2 \\
\cline { 2 - 3 } Rate & .888 & \\
Expression & .780 & \\
Phrasing & .878 & \\
Accuracy & & -.697 \\
Comprehension & & .801 \\
\hline
\end{tabular}

Factor one included the variables that tapped oral reading fluency and accounted for 47 percent of the variance. The second factor consisted of accuracy and comprehension suggesting the presence of an additional factor related to knowing what the words are and ability to extract meaning from the text.

A second factor analysis was completed to determine constructs that arose out of the entire data set. This analysis yielded four factors as can be seen in Table 5. The first 
two factors accounted for 52 percent of the variance. Factor one was a verbal speed construct, made up of skills related to reading fluency, word reading speed, speech rate and accuracy, and speed at naming letters. The second factor was comprised of the syntactic and semantic language measures. Expression loaded on both the first factor, and a separate third factor, accounting for 10 percent of the variance. Finally, reading comprehension also comprised a separate factor and accounted for approximately 10 percent of the variance in the entire data set.

Table 5

Factor Loadings for Passage Reading, Cognitive and Linguistic Measures

Factor $1 \quad$ Factor $2 \quad$ Factor $3 \quad$ Factor 4

Word Recognition Speed .869

Decoding Speed .861

Rapid Serial Naming

Oromotor Accuracy

$-.523$

Reading Rate

.815

Phrasing*

Expression* .632

Listening Comprehension

Syntax Judgment

Reading Comprehension*

* variables entered in the factor analysis in their transformed form. Note: only factor loadings $>.50$ are given. Working memory did not load on any factor, but approached significance on factor 1 . Oromotor speed did not load significantly on any factor.

Taken in conjunction, results from these factor analyses suggest the importance of looking at fluency separately from other reading skills. Also, these results show that an examination of skills related to fluent reading ability should include two primary constructs: (1) a speed construct consisting of skills related to word reading speed, text 
reading speed, speech rate and accuracy, and naming speed; (2) syntactic and semantic language skills.

\section{Multiple Regression Analyses}

Hierarchical Multiple Regression analyses were carried out to examine the variance in the different passage reading variables (i.e., rate, phrasing, expression) accounted for by the language and cognitive factors, and other reading measures.

Regression analyses of measures that would predict reading rate were completed first. Age and independent reading level were entered first as a means to control for their influence. The variables entered into the analyses next were chosen because they had high loadings with the verbal speed construct reflected in the factor analysis. In addition, working memory was also entered as an independent variable because the correlational analysis showed that rate and working memory were significantly related $(r=.36, p<.00)$. The following variables, in addition to age and reading level, were entered: word recognition speed, decoding speed, rapid serial naming, oromotor accuracy, and working memory.

Regression diagnostics, including an examination of the residual scatterplot (see Figure 1), showed that this model met the assumptions of linearity, normality, and homoskedasticity. In addition, outliers were not evident on the plot. A further examination of Cook's values and leverage points confirmed that no significant multivariate outliers or other overly influential points were present in the model. 
Figure 1

Scatterplot of Residuals of Regression Model Predicting Reading Rate

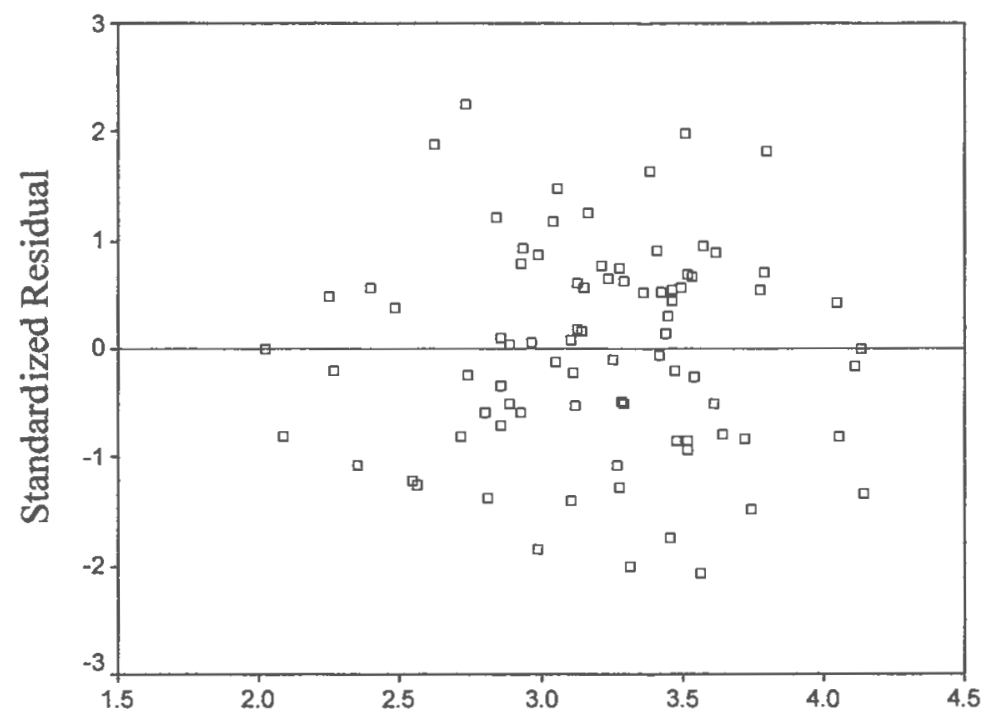

Unstandardized Predicted Value

The results from this model can be seen in Table 6. Though controlling for age seems to be somewhat important, the variance accounted for by age did not reach significance. On the other hand, there was a significant relationship between independent reading level and reading rate.

Next, even with independent reading level already accounted for, word reading skills reflected in word recognition speed and decoding speed, made a significant contribution to the variance in reading rate. Furthermore, the effects of word recognition speed contributed significantly to the model whether entered before or after decoding speed. This is not surprising given that word recognition speed is a more advanced reading skill than decoding.

An order of entry effect was evident when rapid serial naming and oromotor accuracy were varied. When rapid serial naming was entered first, the effects of 
Table 6

Hierarchical Multiple Regression Analysis of Predictors of Reading Rate

\begin{tabular}{llcccc} 
Step & Measure & $\mathrm{R}^{2}$ & adjusted $\mathrm{R}^{2}$ & $\mathrm{R}^{2}$ change & $\begin{array}{c}\text { Significance of } \\
\text { change in F }\end{array}$ \\
1. & Age & .04 & .03 & .04 & .07 \\
2. & Ind. Reading Level & .26 & .24 & .22 & .00 \\
3. & Word Rec. Speed & .53 & .51 & .27 & .00 \\
4. & Decoding Speed & .53 & .50 & .00 & .84 \\
\hline \multicolumn{5}{c}{ Reversing order of 3 and 4 }
\end{tabular}

\begin{tabular}{|c|c|c|c|c|c|}
\hline 3. & Decoding Speed & .38 & .36 & .12 & .00 \\
\hline 4. & Word Recog. Speed & .53 & .50 & .15 & .00 \\
\hline 5. & Rapid Serial Naming & .54 & .51 & .01 & .17 \\
\hline 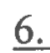 & Oromotor Accuracy & .54 & .51 & .01 & .37 \\
\hline
\end{tabular}

Reversing order of 5 and 6

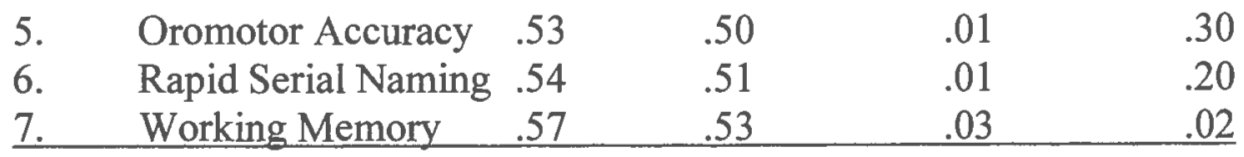

Entering 3 and 4 last

\begin{tabular}{|c|c|c|c|c|c|}
\hline 1 . & Age & .04 & .03 & .04 & .07 \\
\hline 2. & Ind. Reading Level & .26 & .24 & .22 & .00 \\
\hline 3. & Oromotor Accuracy & .27 & .24 & .01 & .27 \\
\hline 4. & Rapid Serial Naming & .34 & .30 & .07 & .01 \\
\hline 5. & Working Memory & .38 & .34 & .05 & .02 \\
\hline 6. & Decoding Speed & .42 & .37 & .03 & .04 \\
\hline 7. & Word Recog. Speed & .57 & .53 & .16 & .00 \\
\hline
\end{tabular}

Deleting 1 and entering 2 last

\begin{tabular}{|c|c|c|c|c|c|}
\hline 1. & Oromotor Accuracy & .12 & .11 & .12 & .00 \\
\hline 2. & Rapid Serial Naming & .25 & .23 & .12 & .00 \\
\hline 3. & Working Memory & .30 & .29 & .06 & .01 \\
\hline 4. & Decoding Speed & .39 & .35 & .08 & .00 \\
\hline 5. & Word Recog. Speed & .52 & .49 & .14 & .00 \\
\hline & Ind. Reading Level & .55 & .51 & .02 & .05 \\
\hline
\end{tabular}

oromotor accuracy were not strong, but they improved when entered ahead of rapid naming. This is also a reasonable finding given previous research suggesting that rapid serial naming is moderated somewhat by articulation and oromotor planning. 
When decoding and word recognition speed were entered last, the effects of rapid serial naming and working memory increased a great deal indicating shared variance. Similarly, when the effects of age were eliminated and independent reading level was entered last, the contribution made by the other variables also increased significantly, including oromotor accuracy, though it was not a statistically significant predictor in the previous models. Therefore, measures of working memory, oromotor accuracy, and rapid serial naming share variance with word-level reading skills and independent reading level, and they are significantly related to reading rate.

Overall, based on this hierarchical analysis, the independent variables entered into this model were effective in accounting for a significant portion (i.e., 53 percent) of the variance in reading rate. When age was eliminated as a covariate and independent reading level entered last, the predictors still contributed significantly to rate (approximately 51 percent).

Hierarchical Multiple Regression analyses were also conducted to determine which variables are the best predictors of phrasing skills in oral reading. In this set of analyses, the variables that loaded onto both the verbal speed and the language constructs from the previous factor analyses were selected for entry and diagnostics were run. Based on a scatterplot of the residuals, this model met the assumptions of linearity, normality, and homoskedasticity, but three multivariate outliers were identified. Their distance from the sample was confirmed with an examination of Cook's values. No leverage points were identified. The residual scatterplot with outliers removed can be seen in Figure 2, and the results of the regression are presented in Table 7. 
Figure 2

Scatterplot of Residuals for Phrasing Regression Model

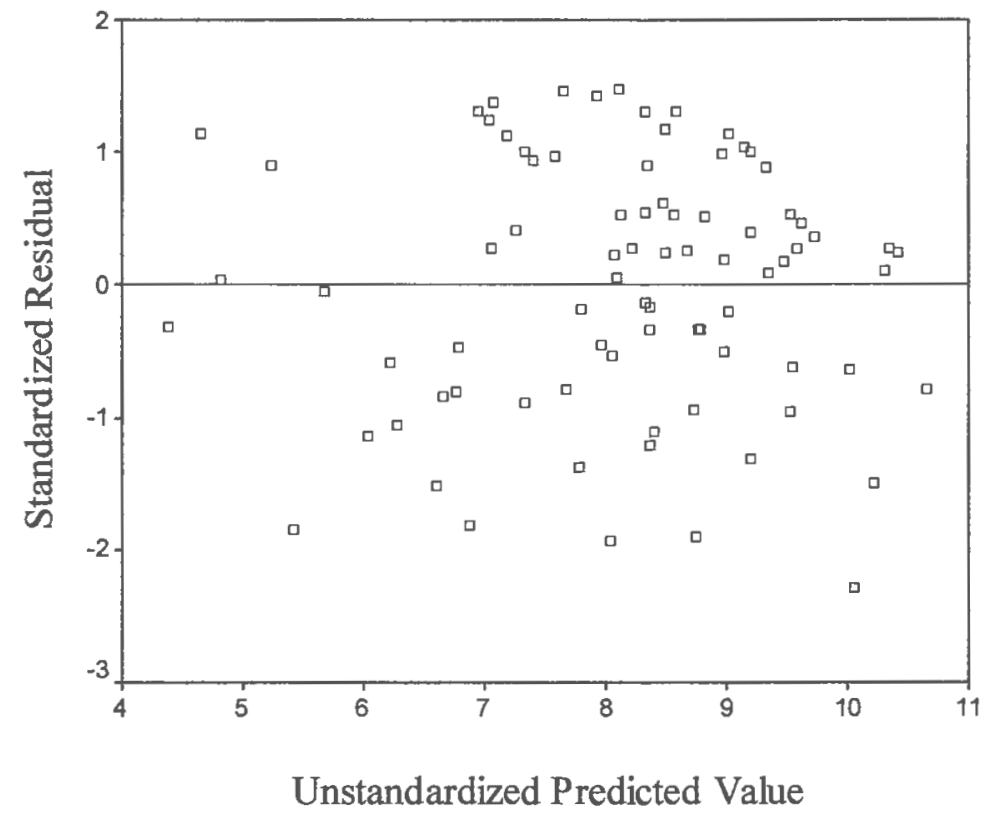

In this model, decoding and word recognition were entered last to determine how much variance was accounted for by the other cognitive and linguistic variables. It seems that regardless of entry order, oromotor accuracy and rapid serial naming account for significant amounts of variance in the ability to read in appropriate phrases. However, syntax judgment and listening comprehension do not. Though they account for greater variance when entered ahead of word recognition and decoding, their influence on the model is not significant in either position and is less of a determinant in phrasing than word level skills. Also noteworthy is the fact that age and reading level accounted for a greater amount of variance in this model predicting phrasing ability than they did in the model predicting reading rate. 
Table 7

Hierarchical Multiple Regression Analysis of Predictors of Phrasing

Step Measure $\quad R^{2}$ adjusted. $R^{2} \quad R^{2}$ change $\begin{aligned} & \text { Significance of } \\ & \text { change in } F\end{aligned}$

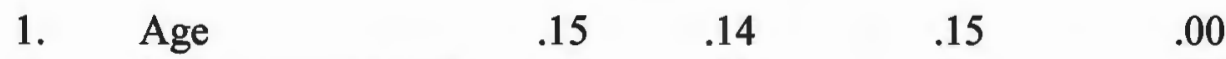

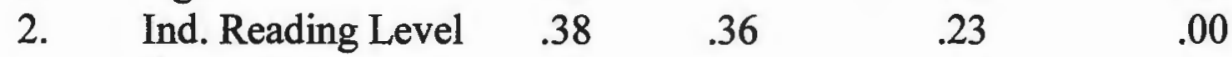

3. Syntax Judgment $\quad .40 \quad .38 \quad 03 \quad .08$

4. List. Comprehension $\quad .41 \quad .38 \quad 01 \quad .01$

5. Oromotor Accuracy $\quad .45 \quad .41 \quad 04 \quad .04$

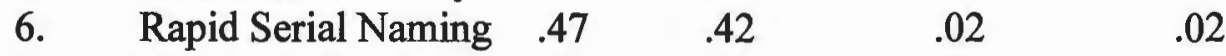

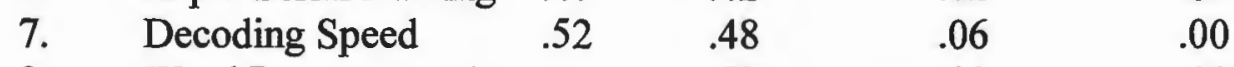

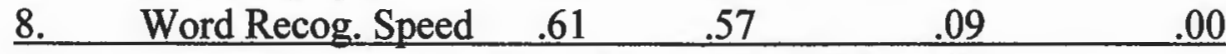

varying entry position of 7 and 8

\begin{tabular}{|c|c|c|c|c|c|}
\hline 1 . & Age & .151 & .140 & .151 & .000 \\
\hline 2. & Ind. Reading Level & .377 & .361 & .226 & .000 \\
\hline 3. & Decoding Speed & .492 & .472 & .115 & .000 \\
\hline 4. & Word Recog. Speed & .542 & .518 & .050 & .006 \\
\hline 5 . & Syntax Judgment & .551 & .521 & .009 & .226 \\
\hline 6. & List. Comprehension & .555 & .518 & .004 & .428 \\
\hline 7. & Oromotor Accuracy & .585 & .545 & .030 & .026 \\
\hline 8. & Rapid Serial Naming & .611 & .567 & .026 & .03 \\
\hline
\end{tabular}

Finally, regression analyses were conducted to predict expression. Hierarchical Multiple Regressions were completed first, using the same independent variables used in the model to predict phrasing. The model was assessed to verify that it met the primary assumptions. As can be seen in Figure 3, the model did not meet the assumptions of homoskedasticity or normality. Therefore, no further analyses with the measure of expressive quality were conducted.

\section{Non-parametric Tests}

In order to evaluate the relationships between reading comprehension and reading rate, phrasing, and expression, chi square analyses were conducted. Prior to the analyses, 
all variables were converted to groups (see Table $8 \mathrm{a}-\mathrm{d}$, for explication of the conversion procedures). The results of the chi square analysis for reading comprehension and reading rate were insignificant (see Table 9 , a-c).

Figure 3

Scatterplot of Residuals of Expression Regression Model

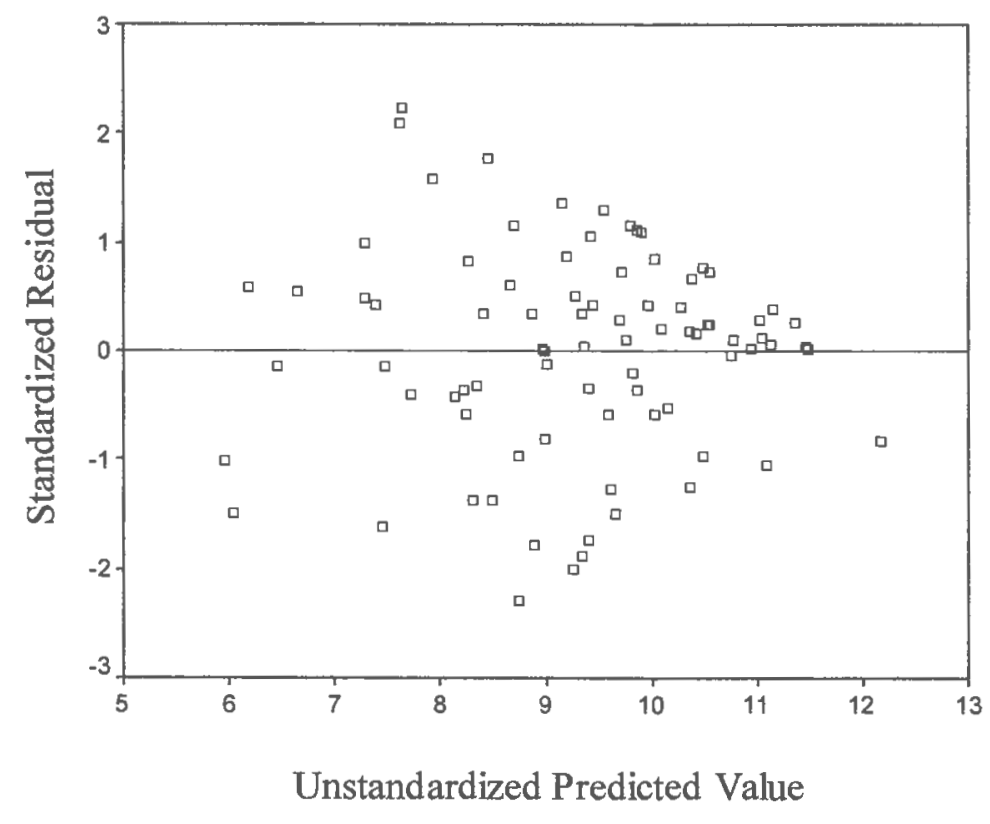

No significant relationship was noted between the speed with which participants read and his or her ability to understand the meaning of the passage $\left(X^{2}(2)=2.13, p=\right.$ .35). Similarly, the results of the chi square analysis with comprehension and phrasing were also insignificant $\left(\mathrm{X}^{2}(2)=.01, \mathrm{p}=.99\right)$. The chi square with comprehension and expression $\left(\mathrm{X}^{2}(2)=4.38, \mathrm{p}=.11\right)$ demonstrated that the relationship between these variables with this sample was not significant. 
Table 8

Conversion of Continuous to Categorical Variables

a. Conversion of Comprehension Raw Score to Categories

Comprehension Percentage

Questions Correct of group

Category

$\begin{array}{lll}7 / 8 \text { or } 8 / 8 & 59.0 & \text { High } \\ 6 / 8 \text { or less } & 41.0 & \text { Medium }\end{array}$

b. Conversion of Rate Raw Score to Categories

$\begin{array}{lll}\text { Rate (SPS) } & \begin{array}{l}\text { Percentage } \\ \text { of Group }\end{array} & \text { Category } \\ \geq 3.54 & 31.3 & \text { Fast } \\ 2.91-3.53 & 36.2 & \text { Medium } \\ \leq 2.90 & 32.5 & \text { Slow }\end{array}$

c. Conversion of Phrasing Ratings to Categories

Phrasing Percentage

Rating of Group Categories

$\begin{array}{lll}\geq 9.23 & 30.1 & \text { Good }\end{array}$

$\begin{array}{lll}7.58-9.22 & 35.0 \quad \text { Adequate }\end{array}$

$\begin{array}{lll}\leq 7.57 & 34.9 & \text { Poor }\end{array}$

d. Conversion of Expression Ratings to Categories

Expression Percentage

Rating of Group Categories

$\begin{array}{lll}\geq 10.71 & 31.3 & \text { Good }\end{array}$

$8.79-10.70 \quad 32.6 \quad$ Adequate

$\begin{array}{lll}\leq 8.78 & 36.1 & \text { Poor }\end{array}$ 
Table 9

Chi Square Analyses of Comprehension

a. Chi Square of Comprehension and Rate

Comprehension

Reading Rate

\begin{tabular}{|c|c|c|c|c|}
\hline & Slow & Medium & Fast & Total \\
\hline \multirow[t]{2}{*}{ Medium } & 8 & 14 & 12 & 34 \\
\hline & $9.6 \%$ & $16.9 \%$ & $14.5 \%$ & $41 \%$ \\
\hline \multirow[t]{2}{*}{ High } & 19 & 16 & 14 & 49 \\
\hline & $22.9 \%$ & $19.3 \%$ & $16.9 \%$ & $59 \%$ \\
\hline \multirow[t]{2}{*}{ Total } & 27 & 30 & 26 & 83 \\
\hline & $32.5 \%$ & $36.1 \%$ & $31.3 \%$ & $100 \%$ \\
\hline
\end{tabular}

b. Chi Square of Comprehension and Phrasing

Comprehension

Phrasing Rating

\begin{tabular}{|c|c|c|c|c|}
\hline & Poor & Adequate & Good & Total \\
\hline Medium & 12 & 12 & 10 & 34 \\
\hline & $14.5 \%$ & $14.5 \%$ & $12.0 \%$ & $41 \%$ \\
\hline $\mathrm{gh}$ & 17 & 17 & 15 & 49 \\
\hline & $20.5 \%$ & $20.5 \%$ & $18.1 \%$ & $59 \%$ \\
\hline tal & 29 & 29 & 25 & 83 \\
\hline & $34.9 \%$ & $34.9 \%$ & $30.1 \%$ & $100 \%$ \\
\hline
\end{tabular}

c. Chi Square of Comprehension and Expression

Comprehension

Medium

$\underline{\text { High }}$

Total Expression Rating

Adequate

13

$15.7 \%$

17 $20.5 \%$

30

$36.1 \%$

7

$8.4 \%$

20

$24.1 \%$

27

$32.5 \%$ $\frac{\text { Good }}{14} \quad \frac{\text { Total }}{34}$

$16.9 \% \quad 41 \%$

$12 \quad 49$

$14.5 \% \quad 59 \%$

$26 \quad 83$

$31.3 \% \quad 100 \%$ 


\section{Chapter IV}

\section{DISCUSSION}

The purpose of this study was to evaluate cognitive, linguistic, and reading skills necessary for fluency, and to gain a better understanding of the contribution made by the different aspects of fluency to reading comprehension. Previous research has shown a strong relationship between fluent reading ability and word reading skills, with limits in decoding and word recognition impeding fluent reading. Therefore, a specific effort was made in this project to evaluate the fluent reading ability of children when word reading skills were not a stumbling block. This was done by finding the independent reading level of each participant and evaluating the quality of his or her oral reading in terms of rate, phrasing, and expression at that level.

The first set of questions this study intended to answer concerned the cognitive and linguistic skills that contribute to the different aspects of fluent reading: rate, phrasing, and expression. Regression analyses that would have answered this question as it pertains to expression were not conducted, due to problems with the distribution of the variable. Therefore, what follows is a discussion of the predictors of rate and phrasing, and other noteworthy findings in the study.

\section{Skills That Contribute to Reading Rate}

Analyses of the predictors of reading rate were conducted first, and several interesting results emerged. A regression model was created including several cognitive and linguistic skills that predicted reading rate. The model was comprised of verbal processing speed skills (i.e., rapid serial naming, oromotor accuracy when asked to 
perform quickly), reading skills (decoding and word recognition speed), working memory, and other factors (i.e., age and independent reading level). Results from the regression analysis indicated that this model was effective in accounting for a significant portion of the variance in reading rate (approximately 50 percent). This finding confirmed one of the primary hypotheses of this study: in addition to word reading skill, the verbal speed factors tapped by rapid serial naming and oromotor accuracy contribute a significant amount of unique variance to the speed with which one reads material that is at his or her independent reading level.

When the order of entry into the model was varied, an additional subset of interesting results was observed. First, the effects of rapid serial naming skills on reading rate were significant, but only when rapid serial naming was entered ahead of decoding and word recognition speed. This finding supports earlier research linking rapid serial naming with reading rate (Young \& Bowers, 1995; Bowers et al, 1999). A similar effect was observed with working memory and oromotor accuracy. These variables were significant predictors of reading rate, but only when entered ahead of word recognition and decoding speed. That a relationship between working memory and reading rate was identified fits well with cognitive theories of automaticity in reading discussed earlier. In particular, Perfetti and Lesgold (1979) hypothesized that working memory serves as an important moderator in the development of automaticity in reading. The association between working memory and reading rate identified in these results corroborates this theory.

In addition, the variance in rate accounted for by decoding speed was only significant when word recognition was entered after decoding speed. This finding is 
indicative of the variance shared by these two skills. However, it also points to the notion that sight word efficiency, which is what was primarily measured by the word recognition task used in this study, is a more significant predictor of reading rate in good readers than the ability to decode novel words. This suggests that as reading skills advance, automaticity at the word level accounts more for individual differences, leaving word attack skills less important as an underlying contributor to rapid reading, as suggested by LaBerge and Samuels (1974) and others.

Similarly, by varying the order of entry, shared variance between oromotor accuracy and rapid serial naming was also evident; oromotor accuracy was only a significant predictor of rate when it was entered into the model ahead of rapid serial naming. This result corroborates previous findings suggesting that oromotor skills are themselves an underlying component of the skills necessary to perform on rapid serial naming tasks (Scarborough \& Domgaard, 1998; Snyder \& Downey, 1995).

Taken together, the set of findings from the hierarchical regression analyses suggests that working memory, rapid serial naming, and oromotor accuracy play a role in both word recognition and decoding speed, and in the rate with which good readers are able to read connected text. Likewise, automaticity of word-level reading skills is strongly linked with text level speed, as others have found (e.g., Young \& Bowers, 1995; Bowers, Sunseth, \& Golden, 1999).

\section{Skills that Contribute to Phrasing Ability}

Hierarchical multiple regression analyses were also conducted to determine the underlying factors that contribute most significantly to phrasing ability in oral reading. A 
regression model was created comprised of both verbal processing speed skills (i.e., rapid serial naming, oromotor accuracy) and higher level language skills (i.e., syntax knowledge and listening comprehension). Independent measures of reading ability (i.e., decoding and word recognition speed) and other factors (i.e., age and independent reading level) were also included. Results indicated that this model was effective in accounting for a significant amount of the variance in phrasing ability (approximately 57 percent).

Variations of the order in which individual variables were entered into the model, also was informative. First, even with a skill such as phrasing, predicted to be moderated by higher level linguistic processing, it was very important to control for basic word reading skills. Regardless of whether word recognition and decoding speed were entered into the equation earlier or later than other variables, they consistently proved to be significant predictors of phrasing ability. Conversely, syntax judgment and listening comprehension did not. This finding contradicts one of the hypotheses of this study: that syntactic and semantic ability would contribute significantly to the quality of phrasing skills observed in oral reading. It also raises questions about Schreiber's (1980) theory. He acknowledged that word reading skill would mediate phrasing ability. However, he also argued that poor readers are less able to rely on syntactical and morphological cues to guide them as they parse written material due to inherent language deficits. The present findings suggest that phrasing skill may not be related as strongly to higher level language processes, at least in the sample of readers in this study.

Although this finding contradicted hypotheses of this study and earlier theories, it is not entirely surprising given some previous research. For example, Fowler (1988) 
demonstrated that performance on tasks requiring children to judge syntax accuracy was not highly correlated with reading skills. However, an association was found between the ability to correct syntactically inaccurate sentences and various reading skills. An attempt was made in this study to measure the variance accounted for by skill at syntax correction, however descriptive data indicated that the distribution of that measure was significantly negatively skewed. Transformations were not helpful in correcting for normality and the variable was, therefore, deemed inappropriate for statistical analysis. Therefore, it may be that a significant association exists between phrasing ability in oral reading and higher level language skill, but the relationship was not evident from the way in which syntactical skills were measured in this study.

Hierarchical regression analyses predicting phrasing ability were also effective in teasing apart the relative importance of several variables in terms of their contribution to phrasing by altering the order of entry into the model. Results indicated that both oromotor accuracy and rapid serial naming, again, contributed significantly to the variance in phrasing. Moreover, this finding was consistent regardless of whether decoding and word recognition were entered before or after these variables, underscoring the magnitude of the role these verbal speed skills play in predicting phrasing ability.

\section{Other Noteworthy Findings}

One aspect of this project that differed from previous research was the attempt to examine prosodic quality of oral reading. Further, this study individually analyzed two specific elements of prosody, phrasing and expression, separately. Few researchers have considered the importance of prosodic quality at all, but those who have (Allington, 
1983; Young \& Bowers, 1995) have not examined two primary components of this skill individually. In this study, however, a moderately strong correlation was identified between phrasing and expression. A significant number of participants earned discrepant ratings on the phrasing and expression scales. This finding suggests that these two skills are not inextricably linked, and that they may be different enough to warrant assessing them in isolation in any future research.

Another finding that emerged from this study relates to oromotor skills. Both oromotor speed and oromotor accuracy were measured using the same tongue twister task. Oromotor speed was scored by tallying the rate at which participants repeated simple tongue twisters. However, only accurate strings of eight repetitions or more on phonologically simple items were included in the tally (i.e., only error-free strings were counted). Conversely, oromotor accuracy was measured by asking participants to repeat both simple and complex tongue twisters and tallying the number of errors made. Although the purpose of this measure was to test speech accuracy, it also was a speedrelated measure given that subjects were instructed to complete the task as quickly as possible.

What emerged from these results is that oromotor accuracy was highly correlated with reading rate, as well as other reading measures, yet oromotor speed alone was not. Though similar, one primary difference between these two tasks was that oromotor accuracy counted errors on repetitions of phonologically complex tongue twisters. Therefore, these results suggest that requiring complex articulatory skills, perhaps at a fast rate, is more predictive of overall reading rate, independent reading level, quality of 
expression and phrasing, and basic decoding and word recognition skills, while a measure of oromotor speed was not.

This finding corroborates some previous research (Catts, 1986; Stone \& Brady, 1995 ) identifying deficits in the oromotor accuracy of poor readers relative to good readers, and adds to it by suggesting that accuracy (combined with rate) not only differentiates the two groups, but significantly contributes to the rate and phrasing skills of good readers. However, Stanovich (1988) and others (Wolff, Mitchell, \& Ovrut, 1990) found articulatory rate alone also differentiated good and poor readers. The fact that oromotor rate in this study was not associated with reading skills suggests that rate may be a limiting factor in the skills of poor readers, but it is not as strongly associated with the reading skills of good readers. At the same time, in future work it will be important to analyze effects of rate, controlling for effects of accuracy, on production.

\section{General Conclusions Related to Predictors of Reading Fluency Variables}

Examination of the nature of fluency has produced interesting results. First, the factor analysis of passage reading variables identified two separate reading constructs: one that included the variables associated with fluency (i.e., reading rate, phrasing, expression) and the other that included measures of reading comprehension and word reading accuracy. This result demonstrated the importance of examining fluency as an entity separate from other aspects of good reading skills, and points to the coherence of the construct of fluency.

Second, an examination of reading rate and phrasing ability individually also yielded significant findings. Based on regression analyses, it appears as though the 
predictors of reading rate and phrasing are remarkably similar. This finding was substantiated by the factor analytic results mentioned above, as well as significant bivariate correlation coefficients that were reported.

Earlier research also suggested the presence of such a relationship. Young and Bowers (1995) found that for their sample of good and poor readers, rate and accuracy were the most predictive of performance on fluency ratings. The ability to parse sentences (i.e., read in phrases) was a significant predictor of general measures of fluency only if it was entered into a regression equation prior to rate and accuracy, and even then this association was only evident with good readers. Phrasing was not a significant predictor of fluency ratings regardless of order of entry for poor readers. This order of entry effect suggests that rate influences phrasing skill; judgments of phrasing quality may be moderated, at least in part, by the rate of reading in good readers.

Many researchers and theorists have acknowledged the potential importance of phrasing and/or expressive ability, though attempts to study prosodic quality scientifically have been infrequent because of difficulty in measuring such a subjective factor (Torgesen, Rashotte, \& Alexander, 2001). Based on the present results and earlier research, however, two separate conclusions can be drawn. First, it will be important for researchers to continue to study the nature of prosody and its effect on reading fluency. These variables are a significant component of reading skill and in order to gain a better understanding of them further analysis is required. Use of an appropriate scale can minimize measurement difficulties and facilitate further research. The associations and differences between the underlying components of prosody require further scientific clarification. 
On the other hand, an argument also can be made that analysis of these other aspects of fluency (phrasing, expression) is not imperative for the general practitioner or educator concerned with identifying the different aspects of reading abilities in children. Because there was overlap among the predictors of reading rate and phrasing, and because they were significantly correlated, it may be more parsimonious for classroom purposes to measure reading rate as a general estimate of fluent reading skills rather that the specific aspects of prosody as well.

\section{The Elements of Fluency that Relate to Reading Comprehension}

The second question this study was intended to answer related to the influence individual components of fluency have on reading comprehension. What type of variance can be accounted for by rate, phrasing, and expression in the performance on comprehension measures, when word reading accuracy is not an obstacle?

The ability to answer this question was limited by problems with the reading comprehension measure itself. Ceiling effects and lack of standardization data led to limitations with this variable, and assumptions underlying parametric statistics could not be met. Therefore, several chi square analyses were conducted to determine whether reading rate measures, phrasing, and expression ratings varied with reading comprehension skills. However, significant findings were not obtained. The first analysis demonstrated that the reading rate of children who earned high reading comprehension scores was not different from the reading rate of children who earned lower comprehension scores. The second analysis indicated that the phrasing skills also did not differ for children who earned low versus high comprehension scores. Finally, 
low versus high comprehenders also did not differ on ratings of expressive quality of their oral reading to a significant degree. Furthermore, it should be noted that significant relationships between comprehension and the three fluency variables also did not emerge from bivariate correlational analyses performed on data from the sample as a whole.

One of the hypotheses of this study was that significant relationships would emerge, particularly between reading rate and comprehension. Therefore, these results are in contrast to those hypothesized relationships. In addition, these results contradict previous research identifying strong correlations between reading rate and comprehension in a sample of disabled readers (Fuchs, et al 1998, cited in Fuchs et al, 2001). One possible reason for the different findings may relate to differences in the samples studied. The subjects in this study were not disabled. Furthermore, they were asked to read at a level that was relatively easy for them in terms of decoding demands. Therefore, any lack of a relationship between comprehension and fluency variables in this study, reading rate in particular, may speak to differences in terms of the predictors of ability to extract meaning from written material between good and poor readers, and/or easy versus difficult text.

This suggestion can be further supported by results from a correlational analysis that examined the relationships among variables measured in this study by splitting the entire data set into independent reading level groups. With this analysis, comprehension was found to be significantly associated to reading rate, phrasing, and expression in the lowest reading level measured - second grade - but not for the other three reading level groups. This result must be interpreted with caution due to the relatively small sample 
sizes available within each of the individual groups, but does corroborate the notion of different skills associated with different developmental levels of reading.

The fact that comprehension could not be predicted by the fluency skills measured in this study was particularly surprising. What was even more surprising was the fact that significant correlations were obtained between reading comprehension performance and word reading accuracy within the passage itself, as well as decoding and word recognition speed on independent measures. Negative correlations between word reading skills and comprehension are highly unusual. It has been repeatedly documented in previous research that word reading ability is one of the primary predictors of reading comprehension. Indeed, Gough and Tunmer's (1986) Simple Theory of Reading purports that word reading skills can account for up to half of the variance seen in performance on comprehension measures.

The reason for this unique finding is not clear. The present findings pertaining to comprehension may be an artifact of the sample selected for participation in this study and the type of measure that was used to assess comprehension skill, issues that will be discussed further below. It also can be extrapolated, however, that when good readers make word-level errors, the nature of the errors is such that they do not interfere with the ability to understand the text. For example, in the third-grade passage used in this study, the word "chimps" was printed, but was often read by these participants as "chimpanzees." Clearly this is an error, but one that may not necessarily work against the reader when it comes to comprehension. 


\section{Limitations of This Study}

Several problems arose in this study pertaining to two specific issues that resulted in decreased variability on some of the skills that were measured. First, this study was specifically designed to examine various aspects of reading skill, when the influence of basic word reading ability, one of the most fundamental components of reading success, was eliminated. Controlling for this factor was a conscious choice, as it was hypothesized that it would allow for a less contaminated observation of other reading factors pertaining to fluency. However, what resulted instead was high performance on the other reading skills that were assessed. This led to decreased variability in some cases, and therefore decreased validity of some statistical analyses.

Second, the children who were selected to participate in this study live in a community that generally places a strong emphasis on the importance of education and the attainment of academic success. Many of the parents of these children are themselves well-educated and earn salaries placing them within a high socio-economic range. An examination of the descriptive statistics of the variables that were administered revealed that performance on all standardized measures, as a whole, was above the national normative data published in the test manuals. That fact in itself did not pose any problems as the distributions of these variables were still normal. However, similarly strong performance on some of the non-standardized tests that were administered was a greater hindrance.

As a likely result of these two issues (i.e., study design and sample characteristics), the distributions of several variables measured in this study were negatively skewed, and/or a ceiling effect was observed. In some cases, it was possible to 
successfully transform those variables to increase normality. However, for others, namely syntax correction, expression, and reading comprehension, transformations were not successful. What follows is a discussion of each one in turn.

Previous research suggested that measurements of syntax correction are more highly correlated with reading skill than awareness of syntax accuracy (Fowler, 1988). However, performance on the syntax correction measure used in this study was very strong for almost all participants. On the whole, it did not yield enough variability to meet the assumptions required for valid statistical analysis. Consequently, it had to be eliminated from the data set, leaving only syntax judgment as a potential predictor variable. Because syntax judgment has been shown to be less associated with reading skill, a thorough analysis of the importance of syntax skills in general, in their ability to predict certain aspects of reading fluency was compromised.

Analyses of issues related to reading comprehension were also compromised in this study. In order to measure reading comprehension, participants were asked to answer eight questions about passages they read aloud. The majority of participants answered six or more questions correctly, resulting in a skewed distribution and decreased variability. As discussed earlier, none of the hypothesized relationships among the reading comprehension and fluency variables were observed. It is highly unlikely, however, that this means that a relationship does not exist. Rather, it is more probable that this finding reflects the fact that this sample of children did exceedingly well on this measure, thereby limiting the variance and rendering it difficult to observe any possible relationships. 
It is important to note, however, that strong performance on the comprehension measure may be a function of another issue. When basic reading skills are strong, as they were for the participants in this project, other factors likely come into play to influence the quality of reading comprehension skill. For example, prior knowledge is known to be an important predictor of the ability to comprehend written material (Leslie \& Caldwell, 2001). Given the nature of this sample, it can be hypothesized that their level of prior knowledge as a group was high, a factor not controlled for in this study that may have confounded the results.

Finally, ratings of expressive quality also were likely to have been confounded by certain aspects of the design of the study. Again, the general level of performance on this measure was very good. The majority of participants read the designated passages with appropriate expression given the syntactic and semantic context. As a result, uniformly high performance led to decreased variability in the sample on this measure, so much so that the stability of statistical analyses was reduced. This result does suggest that when decoding errors are not significant, the ability to project appropriate expression is increased, underscoring the importance of basic word reading ability in all aspects of fluent reading. One additional point is that because this rating system was designed specifically for this project, the reliability of the scale could be questioned. However, the estimate of inter-rater reliability for the rating scale was very high. It seems, therefore, that the rating scale itself still may be a useful tool for measuring reading expression, and that problems encountered with the variable are likely a function of the study design and the importance of word reading ability in predicting performance. 
Issues related to the lack of variance of the measures could be addressed by conducting a cross validation study with a different sample of children. By applying the statistically significant regression models identified in this study to a different sample of children, it is possible that changes in the strengths of the relationships could be obtained. It is not certain whether those relationships would increase or decrease; typically smaller correlations are expected with cross-validation research. However, because the strict design criteria in the present study (i.e. children reading at their independent reading levels) may have reduced variability, such a project may actually reveal stronger relationships.

A different, but related concern with this study again concerns the cultural and socio-economic characteristics of the sample investigated. An argument can be made for studying an ethnically homogeneous population, particularly because of the ability of such a design to limit any variance that may arise as a result of the cultural diversity. However, given the nature of our national population and the need for research that can be generalized to a broad and diverse population, such an argument has limits. While the significant findings of this study are valuable, caution should be used when attempting to relate them to children who do not parallel the characteristics of this sample.

Another separate issue and limitation that arose in this study relates to the fact that students were asked to read narrative passages at different levels. Again, this was a conscious decision related to the questions targeted in the study. This element of the design was intended to ensure that all of the participants were reading with a high level of decoding and word recognition accuracy. However, the variation in independent reading level of the participants was relatively broad, and it is not clear how this affected results. 
Attempts were made to examine differences that might have come about as a result of the difficulty level of the text being read. As reported earlier, partial correlations did not yield noteworthy findings with regard to this potential confound. On the other hand, an examination of bivariate correlations, with the entire data set split into reading level groups, did suggest differences in relationships between some variables as a result of the level of text being read. As mentioned earlier, however, these results should only point to potential questions for future research, as the sample sizes within each of the groups in this study were too small to be statistically reliable.

\section{Suggestions for Future Research}

Based on the results of this study, as well as some of the limitations that have been discussed, one suggestion for future research is certainly to continue exploring the nature of reading fluency. There are good reasons to continue the investigation into the role fluency plays in performance on reading comprehension measures, in particular. Although Gough and Tunmer's (1986) simple theory of reading is informative, it seems likely that incorporating certain aspects of fluency, especially reading rate and prosody, into the model might further improve its ability to predict successful reading comprehension. Though the results of this study cannot confirm that hypothesis, future research to investigate that possibility would be worthwhile.

Furthermore, this study, as well as previous research, has yielded findings to indicating of great differences between the underlying cognitive and linguistic skills necessary for the different facets of fluent reading between good and poor readers, and early and advanced readers. This study targeted third- and fourth-grade readers because 
that is the point at which fluent reading is expected in classrooms. The reading goals of teaching have shifted from an emphasis on the development of basic reading skills, to an emphasis on the use of those skills to learn new information. However, a range of fluency skills was obtained for children in this age range in this project. Therefore, more studies that compare the underlying skills related to fluency in children at different developmental levels with respect to reading are recommended.

There also appear to be differences associated with both the absolute difficulty level of the text being read, as presented by Young and Bowers (1995), and the difficulty level relative to individuals as presented in this study. No study thus far has specifically identified the relative difficulty level of the material other than this one, yet preliminary analyses suggest that this may have played a role in some of the results presented. Coincidently, during the data collection phase of this study, information was gathered regarding the skills of participants reading passages that were at his or her instructional level (i.e., 90 to 98 percent of words read accurately). An examination of this data is planned, asking similar questions related to the underlying constructs of the different aspects of fluency that were asked in this study.

\section{Closing Remarks}

In summary, several conclusions can be drawn from the results of this study that both corroborate earlier research and theories and point to new directions for future scientific study. First, the importance of examining fluency as a separate component of general reading ability was underscored by the results of this study. Variables that pertain to fluency (i.e., rate, phrasing, and expression) are distinct from other aspects of 
reading skill (i.e., comprehension and word-level accuracy) and need to be considered independently.

Second, word recognition and decoding speed are significant predictors of the different aspects of fluency (i.e., rate and phrasing), and word recognition speed accounts for a significantly greater amount of variance than ability to decode novel words. In addition, other cognitive skills contribute to the variance in reading rate and phrasing ability. Specifically, rapid serial naming and oromotor accuracy also significantly predict both reading rate and phrasing ability in children reading at his or her independent reading level.

These findings suggest that there are similarities in the underlying cognitive skills necessary for both phrasing and reading rate. However, differences in the underlying factors of rate and phrasing emerged as well. In particular, working memory was a significant predictor of reading rate, but not phrasing. Consequently, the results of this study call for a further exploration of the distinct aspects of reading fluency, not just reading rate alone.

Third, higher level language skills were not predictive of phrasing ability, despite previous research and hypotheses suggesting that they might be. As measured in this study, listening comprehension and syntax knowledge did not significantly contribute to the variance in phrasing skill of oral reading.

Finally, the results of this study underscored the importance of separately examining the elements of prosodic quality in oral reading, phrasing and expression, separately when asking research questions. A moderate correlation between these skills 
was identified in this study, suggesting there is shared variance, but enough unexplained variance between the two was identified to warrant an examination of them in isolation. 
Appendix A

\author{
University of Rhode Island \\ Department of Psychology
}

An Examination of the Nature of Reading Fluency

by Emily Russell, M.A.

\title{
PARENTAL/GUARDIAN CONSENT FOR RESEARCH
}

You are being asked to allow your child to take part in the study described below. If you have questions, either as you read this information or anytime later, please feel free to call Emily Russell, the person conducting this project, at (917) 974-8489 or Dr. Susan Brady, the principle investigator, at (401) 874-4258.

Description of Project: As children learn to read, they gradually become more fluent at reading words and text. In this study we are interested in measuring the oral reading ability of third and fourth graders, as well as several other reading skills and cognitive factors that contribute to its development.

Procedures: If you decide to allow your child to take part in this study, the following will occur. Your child will participate on two separate occasions during the school day at times approved by his or her teacher. In addition, some appointments may be arranged after school hours. If this would work with your schedule, please note that at the bottom of this consent form. The testing will occur in a quiet, distraction-free room in the school. The purpose of the testing will be explained to your child as s/he gets to know the examiner better. On the first day, they will be asked to read a list of words as quickly as possible. This will assist the examiner in determining his or her specific reading level and, subsequently, which oral reading passage to administer to him or her. Then, each child will be asked to read either a third, fourth, or fifth grade narrative reading passage out loud. Performance will be scored for rate, accuracy, and knowledge of phrasal boundaries. Additionally, they will be asked to answer five comprehension questions about the passage, and they will be asked to listen to a similar narrative passages and answer five comprehension questions. On the second day, a number of very brief tasks will be administered. They will be asked to complete a verbal processing speed task, one task tapping articulatory ability and another tapping articulatory rate, and a measure assessing his or her knowledge of syntax structure. Finally, they will also be asked to read a list of nonsense words as quickly as possible to determine his or her ability to decode novel words.

What are the potential risks involved? There are minimal potential risks involved for your child. The nature of the reading tasks to be performed are similar to activities they do in their regular classroom. The nature of the other tasks to be completed are different, interesting, and game-like. Some parts will be very easy, while other parts may be slightly more challenging. However, the tasks have been chosen to be appropriate for your child's age group. Each task is brief, and children typically enjoy doing them.

What are the benefits of this study? One primary benefit of this study is that we will be able to obtain very specific information about the reading skills of your child, information which will be shared with his or her teacher. Additionally, the researchers and school personnel may be able to learn more about the nature of reading development and reading difficulties. This knowledge 
may eventually improve our understanding of assessment and intervention for children with reading problems.

How will confidentiality be maintained? Participation in this study will be completely confidential. No information collected will ever be presented or published with your child's name or any other identifying information. No one beside the researcher, Emily Russell, and the principle investigator, Susan Brady, will have access to the individual score sheets, which will be kept in a secure file cabinet at the University of Rhode Island. This information will, however, be shared with your child's teacher pending your consent. You may also be able to obtain this information from your child's teacher if you wish in the form of a brief summary sheet. If, however, you do not wish to have this information shared with your child's teacher, please contact Emily Russell to let her know.

What about the decision to quit? The decision to take part in this study is completely up to you and your child. Your child does not have to participate. Further, whether you choose to allow your child to be involved will not affect his or her grade or status as a student. If you decide to allow your child to take part, the researcher will explain the project to your child, giving him or her the freedom to ask questions at any time. The researcher will also make it clear to your child that $\mathrm{s} /$ he may quit at any time by telling her or by having his or her parent contact Ms. Russell at (917) 974-8489.

Rights and complaints: If you are not satisfied with the way this study is performed, you may discuss your complaints with Emily Russell anonymously, if you choose. In addition, you may contact Dr. Susan Brady at (401) 874-4285 or the office of the Vice Provost for Graduate Studies, Research and Outreach, 70 Lower College Road, Suite 2, University of Rhode Island, Kingston, RI, 02881, telephone: (401) 874-2635, with any comments, questions or complaints. You should also feel free to contact Kaye May at Coleytown do discuss any concerns you may have.

Thank you very much for taking the time to read over this form. If you understand the information presented above, and any additional questions have been answered for you, please sign below to indicate that your child has your permission to participate in this study.

Name of your child

Signature of Parent/Guardian

Signature of Researcher

Date

Date

(check) __ Yes, I would prefer that my child participate after regular school-day hours. Please call me at to try to arrange this. I agree to be responsible for arranging transportation for this after school participation. 
Appendix B

\section{Tongue Twisters}

1. Clown Nose

2. Black Seal

3. Blue Brush*

4. Four Big Ducks

5. Two Short Chicks*

6. Small Square Stamp*

7. Big Red Stamp

8. Blue Star

9. Shy Seal*

10. Blue Plaid Pants*

11. Brown New Pants

12. Clown Queen*

13. Weak Wrist*

14. Nine Horse Flies

15. Five Fruit Flies*

16. Weak Smile

* denotes complex tongue twister items 


\section{Appendix C}

April 28, 2001

Dear Parents of all Third and Fourth graders,

We are fortunate to have the opportunity to take part in a research study designed to investigate the development of reading skills. Emily Russell, M.A., a doctoral psychology student who is completing an internship this year at Coleytown, is interested in investigating the types of skills necessary for developing fluent reading ability.

As the attainment of reading fluency is an important aspect of the reading goals we have for children in third and fourth grade, I feel that the information that will be obtained in this study will be extremely useful to us in three ways. First, we will be able to collect very specific data on the level of several different kinds of important reading skills of all children who participate. This data will be more detailed than what we can normally attain through typical standardized testing. Second, we will be able to learn more about the underlying reading skills and cognitive functions that predict reading fluency, which can help us be more proactive as educators interested in increasing this skill in our children. Third, Ms. Russell plans to use a measure in her study that we are currently investigating ourselves to use as an assessment tool for teachers. She has promised to share her knowledge of the tool with our staff, which will assist us in our decision making process. Additionally, a review of her results will enable us to learn more about this new measure and how the information it provides can serve our school's purposes.

Attached, I have included a brief description of the study written by Ms. Russell and her academic advisor Susan Brady, Ph.D. I strongly encourage you to take the time to read this information, call either one of them with any questions you may have, and return the consent form to your child's teacher as early as possible. Ms. Russell needs to work with approximately 120 children all together, and she will select her participants on a firstcome first-serve basis.

Thank you very much for your time. Let's celebrate the scientific investigation of how our children learn!

Sincerely,

Kaye May

Principal 
Appendix D

\author{
The University of Rhode Island \\ Department of Psychology \\ An Examination of the Nature of Reading Fluency \\ by Emily Russell, M.A.
}

\title{
ASSENT FROM MINOR FOR RESEARCH
}

(Read to participant by researcher):

You have been asked to participate in a study that is being run by a group of people who are from the Psychology Department at the University of Rhode Island. I am going to tell you about it. Feel free to ask me any questions. If you have more questions later, we can talk about them. Your parent has been told about this project and has given you permission to work with me.

(Description of Project):

This study will look at how kids your age can do a few reading and language tasks. This might help scientists understand why some children have trouble learning to read and others don't.

Here is what will happen. We will meet twice; today and tomorrow. Today I am going to ask you to do a few different reading and listening activities, a lot like what you do in your classroom. You will have to read a list of words, then read a story and answer a few questions about it. Then I will ask you to simply listen to a story from this tape recorder and answer a few questions about it too. Then, tomorrow, I am going to come get you again and ask you do to read a list of words that are not real at all. They are called nonsense words, and they can be pretty funny to pronounce. Then we will do some language games, but I will teach you how to do them first. Remember, you can ask me any questions about what you are doing, and we can take a break whenever you want. can ask me at any time. It will take about a half hour to complete the tasks today, and the same tomorrow.

(Potential risks and the decision to quit):

The things we are going to do are not harmful, and in fact, most kids have fun doing them. Some parts might be very easy for you to do, while other parts may be a little harder, but this is normal. None of the tasks will last very long and I will tell you everything you need to know. But, I want you to know that it is up to you to do these things; you do not have to do them. You may quit at any time. Just let me know if you feel like stopping.

(Benefits and confidentiality):

By doing these activities, it will help scientists learn more about school children, but you are not going to get much for doing them. Even though they should be fun to do, they 
will not help you do better in school. But you will get to choose a prize in the end for working hard and to thank you for helping me out.

After we are done with all of this work, I am going to share with your teacher how everyone in your class did reading the list of words and stories. How you do will not at all be counted on your report card, but it will help your teacher understand how much reading you have learned this year. Everything else you do though, will be kept private. If you want to tell people how you did you can do that, but I will not tell anyone.

(Questions before beginning):

Do you have any questions before we start? Feel free to ask questions at any time, and if you want to quit before we are done, just let me know.

Before we start, I want you to write your name on this piece of paper to for me to show that you understand everything that I have said to you and to show that you don't mind going ahead and taking part.

Student's Name

Researcher's Name Date 
Appendix E

Distributions of Non-Normal Variables

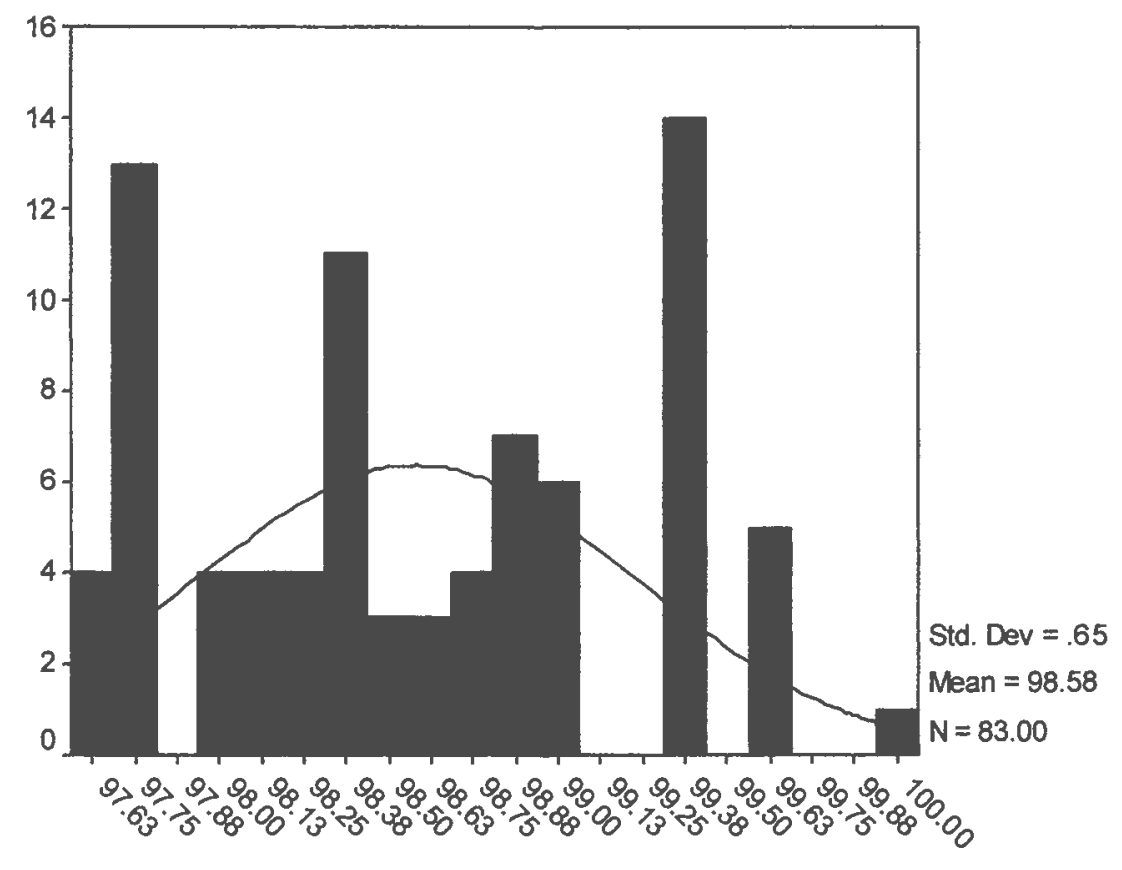

Reading Accuracy

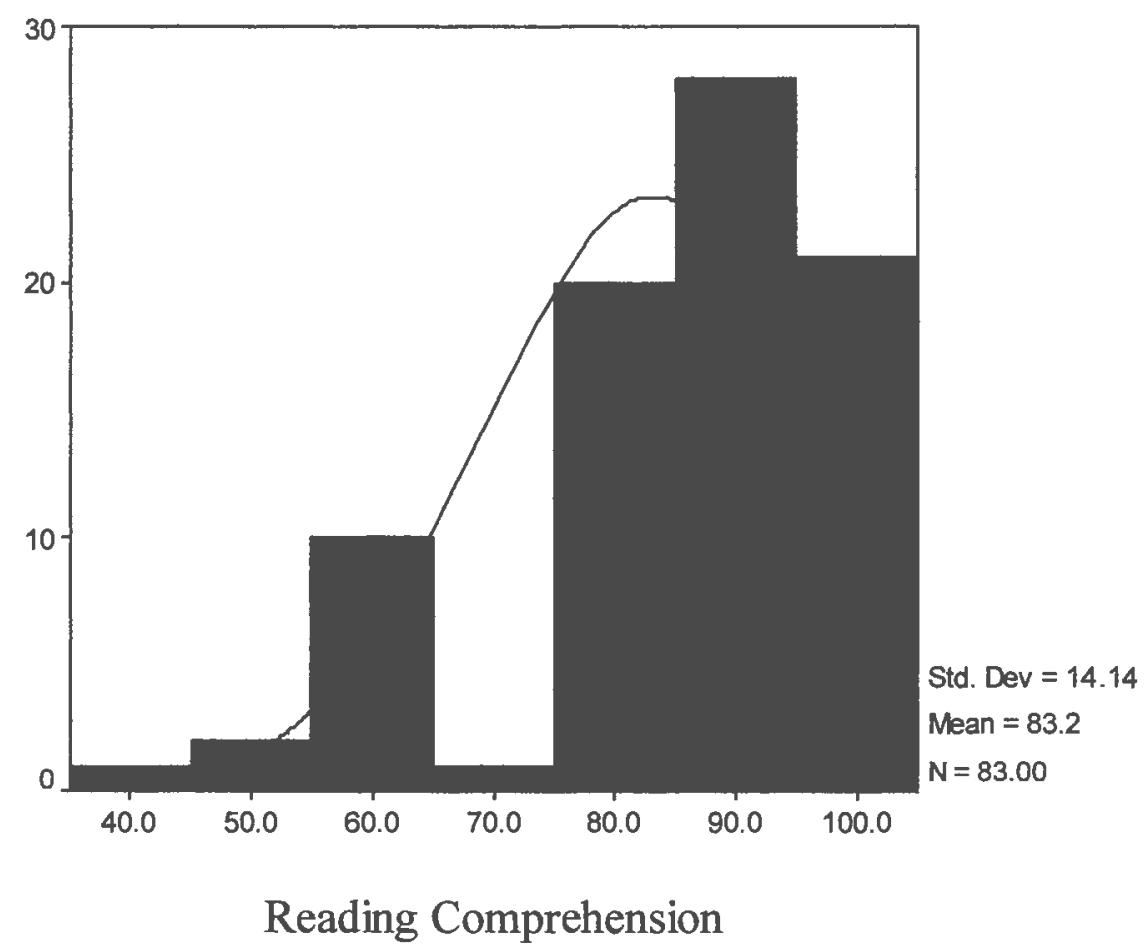




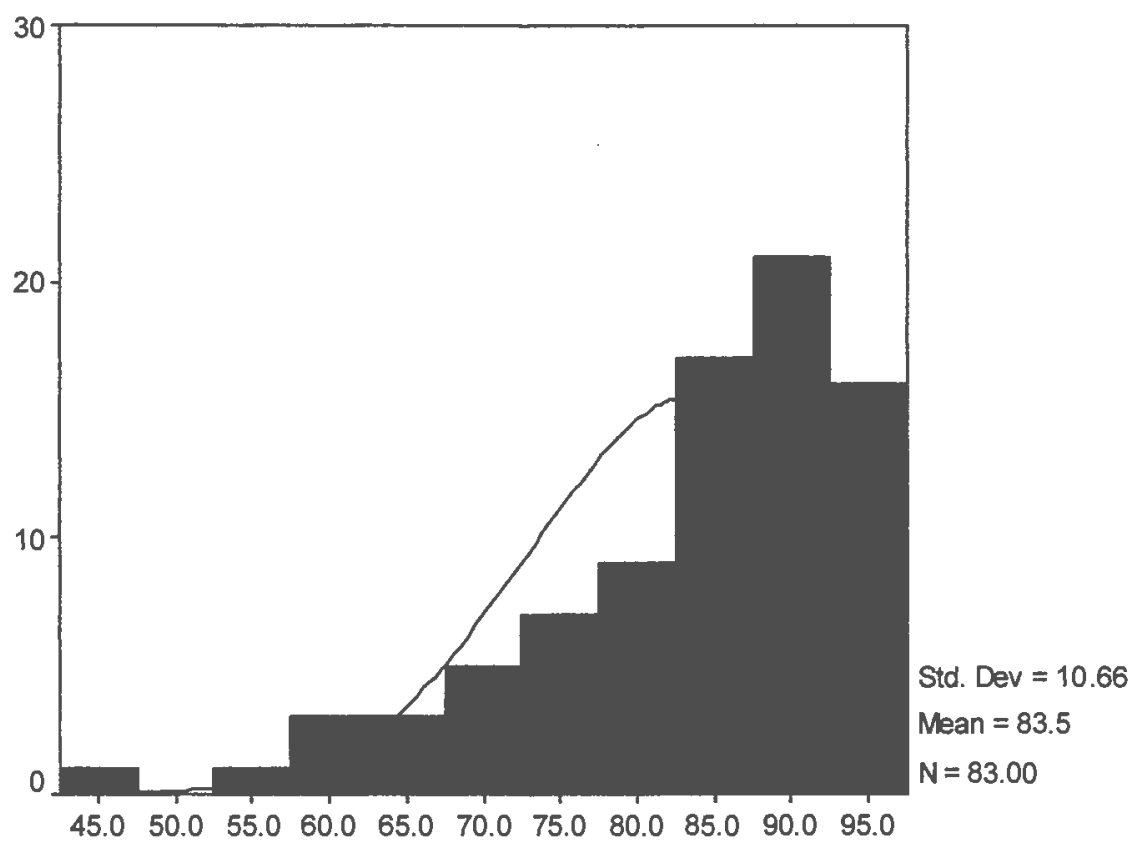

Phrasing

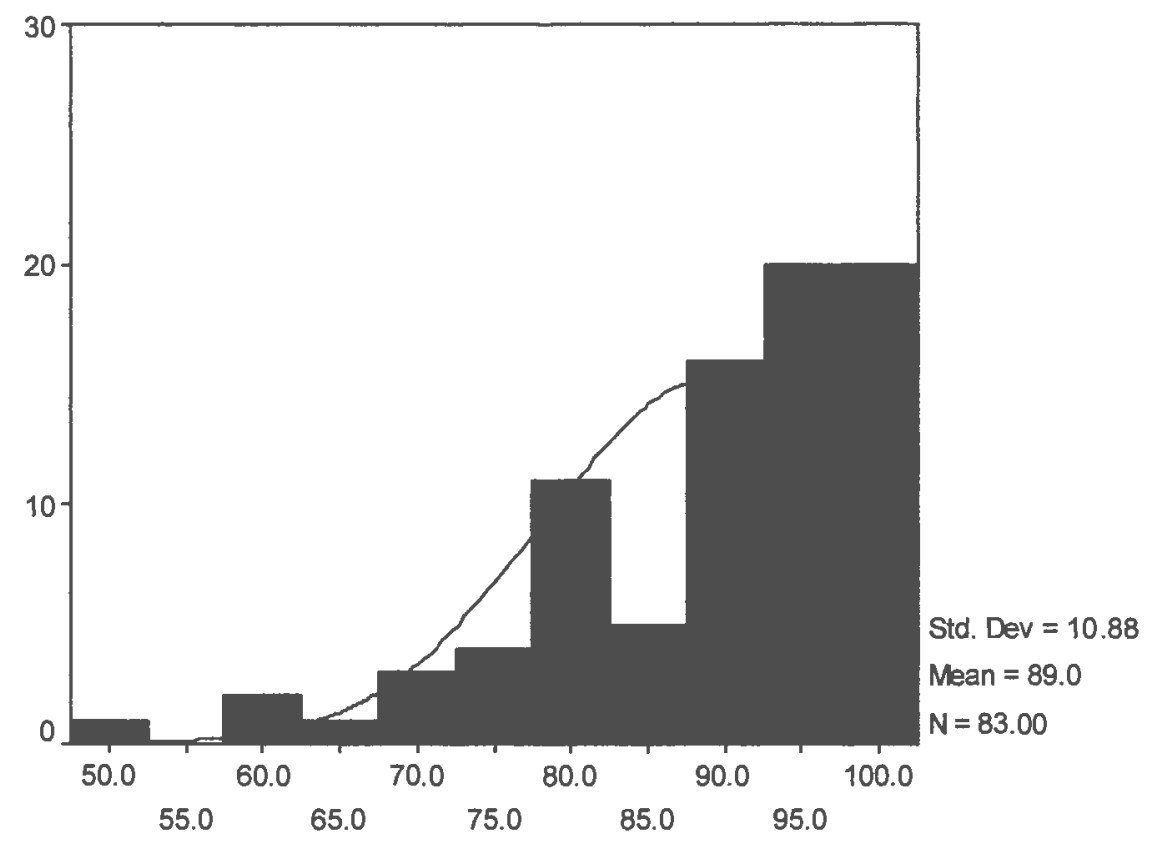

Expression 


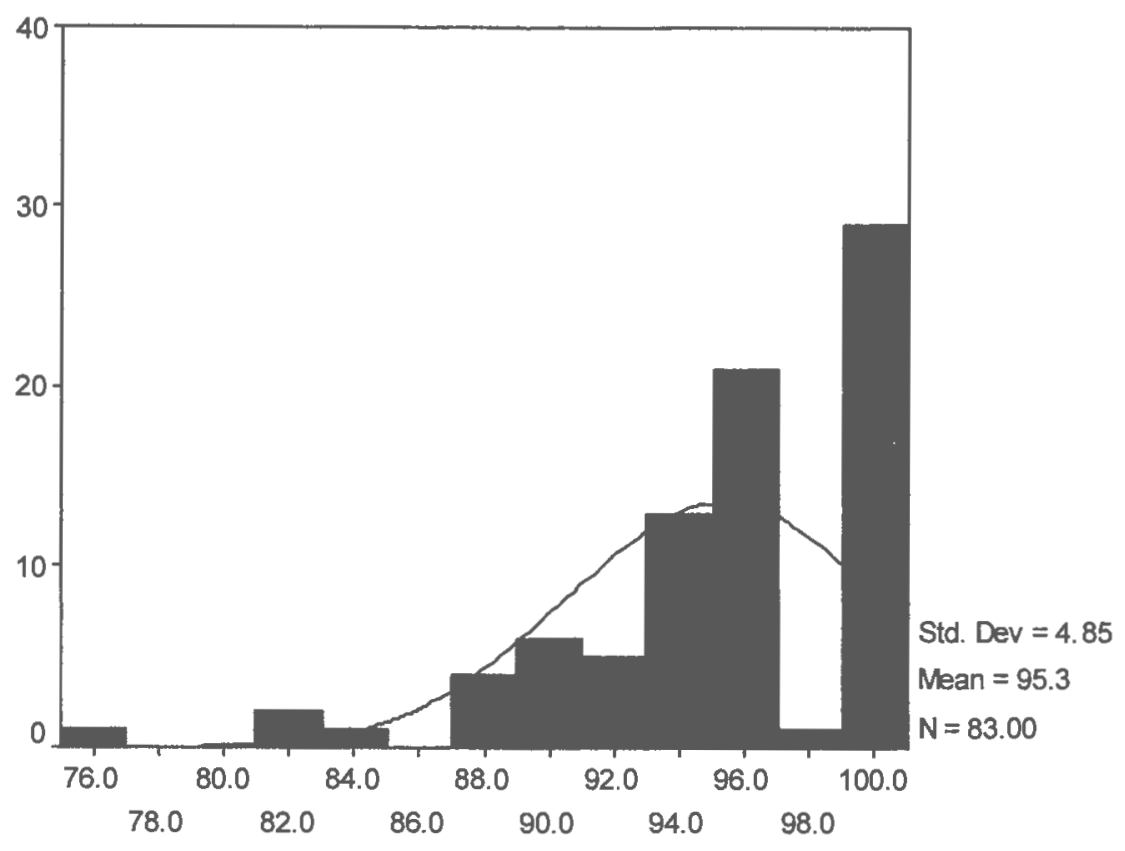

Syntax Awareness - Correction 
Appendix F

Bivariate Correlation Matrix

\begin{tabular}{|c|c|c|c|c|c|}
\hline & Gender & Age & $\begin{array}{l}\text { Reading } \\
\text { Level }\end{array}$ & $\begin{array}{l}\text { Reading } \\
\text { Rate }\end{array}$ & $\begin{array}{l}\text { Reading } \\
\text { Accuracy }\end{array}$ \\
\hline Gender & & $\begin{array}{r}-.12 \\
p=.30\end{array}$ & $\begin{array}{r}-.11 \\
p=.32\end{array}$ & $p=\begin{array}{r}.21 \\
.06\end{array}$ & $p=\begin{array}{r}.31 \\
p=01\end{array}$ \\
\hline Age & $\begin{array}{r}-.12 \\
p=.30\end{array}$ & & $p=00$ & $p=.61$ & $p=.65$ \\
\hline $\begin{array}{l}\text { Reading } \\
\text { Level }\end{array}$ & $\begin{array}{r}-.11 \\
p=.32\end{array}$ & 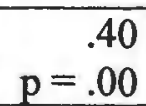 & & $p=.00$ & $p=.23$ \\
\hline $\begin{array}{l}\text { Reading } \\
\text { Rate }\end{array}$ & $p=.06$ & $p=.07$ & $p=.00$ & & $\mathrm{p}=.01$ \\
\hline $\begin{array}{l}\text { Reading } \\
\text { Accuracy }\end{array}$ & $\mathrm{p}=.00$ & $p=.65$ & $\mathrm{p}=.23$ & $\mathrm{p}=.01$ & \\
\hline $\begin{array}{l}\text { Reading } \\
\text { Comprehension }\end{array}$ & 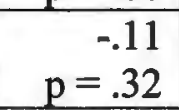 & $\mathrm{p}=.20$ & $\begin{array}{r}-.05 \\
p=.68 \\
\end{array}$ & $\begin{array}{r}-.04 \\
p=.73 \\
\end{array}$ & $\begin{array}{r}-.30 \\
p=.01 \\
\end{array}$ \\
\hline Phrasing & $p=.06$ & $\mathrm{p}=.33$ & $p=.00$ & $p=.00$ & $p=.18$ \\
\hline Expression & $p=.04$ & $\mathrm{p}=.26$ & $p=.00$ & $p=.00$ & $p=.28$ \\
\hline Prosody & $p=.03$ & $p=.00$ & $p=.00$ & $\mathrm{p}=.00$ & $p=.17$ \\
\hline Oromotor Speed & $\begin{array}{r}-.08 \\
p=.49\end{array}$ & $\mathrm{p}=\begin{array}{r}.19 \\
.09\end{array}$ & $\mathrm{p}=.27$ & $p=.06$ & $\mathrm{p}=.05$ \\
\hline $\begin{array}{l}\text { Oromotor } \\
\text { Accuracy }\end{array}$ & $p=.40$ & $\begin{array}{r}-.19 \\
\mathrm{p}=.09\end{array}$ & $\begin{array}{r}-.50 \\
p=.00\end{array}$ & $\begin{array}{r}-.35 \\
p=.00\end{array}$ & $\begin{array}{r}-.13 \\
\mathrm{p}=.25 \\
\end{array}$ \\
\hline $\begin{array}{l}\text { Word } \\
\text { Recognition } \\
\text { Speed }\end{array}$ & $p=.14$ & $\begin{array}{r}-.09 \\
\mathrm{p}=.44\end{array}$ & 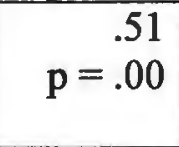 & $p=.00$ & $\mathrm{p}=\begin{array}{l}.28 \\
.01\end{array}$ \\
\hline Decoding Speed & $p=.21$ & $\begin{array}{r}.02 \\
p=.87\end{array}$ & $p=.00$ & $p=\begin{array}{r}.58 \\
.00\end{array}$ & $p=.01$ \\
\hline $\begin{array}{l}\text { Listening } \\
\text { Comprehension }\end{array}$ & $p=\begin{array}{r}-.25 \\
p=.03\end{array}$ & $p=.58$ & $p=.01$ & $p=.23$ & $\begin{array}{r}-.14 \\
p=.20\end{array}$ \\
\hline $\begin{array}{l}\text { Working } \\
\text { Memory }\end{array}$ & $p=.68$ & $\mathrm{p}=.23$ & $p=.06$ & $p=.00$ & $p=.14$ \\
\hline Syntax Judgment & $\begin{array}{r}-.09 \\
p=.43\end{array}$ & $\begin{array}{r}-.08 \\
p=.46\end{array}$ & $p=.04$ & $\mathrm{p}=.03$ & $\mathrm{p}=.32$ \\
\hline $\begin{array}{l}\text { Rapid Serial } \\
\text { Naming }\end{array}$ & $p=.13$ & $p=.03$ & $p=.01$ & 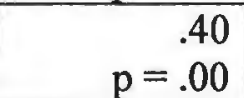 & $p=\begin{array}{r}.33 \\
p=00\end{array}$ \\
\hline
\end{tabular}

* transformed variables used in correlational analysis 
Bivariate Correlation Matrix (continued)

\begin{tabular}{|c|c|c|c|c|c|}
\hline & $\begin{array}{l}\text { Reading } \\
\text { Comprehension }\end{array}$ & Phrasing & Expression & Prosody & $\begin{array}{l}\text { Oromotor } \\
\text { Speed }\end{array}$ \\
\hline Gender & $\begin{array}{r}-.11 \\
p=.33\end{array}$ & $p=.06$ & $p=\begin{array}{r}.23 \\
.04\end{array}$ & $p=.03$ & $\begin{array}{r}-.08 \\
p=.49\end{array}$ \\
\hline Age & $p=\begin{array}{l}.20 \\
.07\end{array}$ & $p=\begin{array}{r}.33 \\
.02\end{array}$ & $p=\begin{array}{l}.26 \\
.00\end{array}$ & $p=\begin{array}{r}.33 \\
.00\end{array}$ & $p=\begin{array}{r}.19 \\
\mathrm{p}=09\end{array}$ \\
\hline $\begin{array}{l}\text { Reading } \\
\text { Level }\end{array}$ & $\begin{array}{r}-.08 \\
p=.68\end{array}$ & $p=\begin{array}{l}.56 \\
p=00\end{array}$ & $p=\begin{array}{r}.54 \\
.00\end{array}$ & $p=\begin{array}{r}.62 \\
p=00\end{array}$ & $p=\begin{array}{r}.27 \\
p=01\end{array}$ \\
\hline $\begin{array}{l}\text { Reading } \\
\text { Rate }\end{array}$ & $\begin{array}{r}-.04 \\
p=.73\end{array}$ & $p=\begin{array}{l}.75 \\
.00\end{array}$ & $\begin{array}{r}.54 \\
p=.00\end{array}$ & $p=\begin{array}{r}.72 \\
.00\end{array}$ & $p=\begin{array}{r}.21 \\
.06\end{array}$ \\
\hline $\begin{array}{l}\text { Reading } \\
\text { Accuracy }\end{array}$ & $p=.01$ & $\mathrm{p}=.18$ & $\mathrm{p}=.28$ & $p=.17$ & $p=\begin{array}{r}.22 \\
.05 \\
\end{array}$ \\
\hline $\begin{array}{l}\text { Reading } \\
\text { Comprehension }\end{array}$ & & $\begin{array}{r}-.01 \\
p=.92\end{array}$ & $\begin{array}{r}-.01 \\
p=.94\end{array}$ & $\begin{array}{r}-.02 \\
p=.89\end{array}$ & $\begin{array}{r}-.09 \\
p=.44 \\
\end{array}$ \\
\hline Phrasing & $\begin{array}{r}-.01 \\
\mathrm{p}=.94\end{array}$ & & $\mathrm{p}=.59$ & $p=.88$ & $p=.18$ \\
\hline Expression & $\begin{array}{r}-.01 \\
p=.93\end{array}$ & $p=\begin{array}{r}.59 \\
.00\end{array}$ & & $p=\begin{array}{r}.90 \\
.00\end{array}$ & $p=\begin{array}{r}.09 \\
.40 \\
\end{array}$ \\
\hline Prosody & $\begin{array}{r}-.02 \\
p=.89 \\
\end{array}$ & $\mathrm{p}=\begin{array}{r}.88 \\
.00\end{array}$ & $\mathrm{p}=\begin{array}{r}.90 \\
.00 \\
\end{array}$ & & $\mathrm{p}=\begin{array}{r}.15 \\
.17\end{array}$ \\
\hline $\begin{array}{l}\text { Oromotor } \\
\text { Speed }\end{array}$ & $\begin{array}{r}-.09 \\
p=.44 \\
\end{array}$ & $p=\begin{array}{r}.18 \\
p=.10\end{array}$ & $\begin{array}{r}.09 \\
\mathrm{p}=.40 \\
\end{array}$ & $p=\begin{array}{r}.15 \\
.17\end{array}$ & \\
\hline $\begin{array}{l}\text { Oromotor } \\
\text { Accuracy }\end{array}$ & $\begin{array}{l}.12 \\
.30 \\
\end{array}$ & $\begin{array}{r}-.45 \\
p=.00\end{array}$ & $\begin{array}{r}-.36 \\
p=.00\end{array}$ & $p=.00$ & $p=.32$ \\
\hline $\begin{array}{l}\text { Word } \\
\text { Recognition } \\
\text { Speed }\end{array}$ & $\begin{array}{r}-.24 \\
p=.03\end{array}$ & $p=\begin{array}{r}.56 \\
.00\end{array}$ & $\mathrm{p}=\begin{array}{r}.47 \\
.00\end{array}$ & $\mathrm{p}=\begin{array}{r}.58 \\
.00\end{array}$ & $p=.31$ \\
\hline $\begin{array}{l}\text { Decoding } \\
\text { Speed }\end{array}$ & $\begin{array}{r}-.23 \\
p=.04\end{array}$ & $p=\begin{array}{r}.55 \\
p=00\end{array}$ & $\mathrm{p}=\begin{array}{r}.41 \\
.00\end{array}$ & $p=\begin{array}{r}.55 \\
.00\end{array}$ & $p=\begin{array}{r}.30 \\
.01\end{array}$ \\
\hline $\begin{array}{l}\text { Listening } \\
\text { Comprehension }\end{array}$ & $\begin{array}{r}.23 \\
p=.04\end{array}$ & $p=\begin{array}{r}.18 \\
p=.11\end{array}$ & $p=\begin{array}{r}.11 \\
p=.31\end{array}$ & $p=\begin{array}{r}.17 \\
p=.14\end{array}$ & $\begin{array}{r}-.10 \\
\mathrm{p}=.39\end{array}$ \\
\hline $\begin{array}{l}\text { Working } \\
\text { Memory }\end{array}$ & $p=\begin{array}{r}.02 \\
.88\end{array}$ & $p=\begin{array}{r}.20 \\
p=07\end{array}$ & $p=.33$ & $p=\begin{array}{l}.16 \\
p=14\end{array}$ & $p=.18$ \\
\hline $\begin{array}{l}\text { Syntax } \\
\text { Judgment }\end{array}$ & $p=.96$ & $p=.02$ & $p=.42$ & $\mathrm{p}=.09$ & $\begin{array}{r}-.01 \\
p=.90 \\
\end{array}$ \\
\hline $\begin{array}{l}\text { Rapid Serial } \\
\text { Naming }\end{array}$ & $p=.20$ & $\mathrm{p}=.01$ & $p=.02$ & $p=.01$ & $p=.00$ \\
\hline
\end{tabular}


Bivariate Correlation Matrix (continued)

\begin{tabular}{|c|c|c|c|c|}
\hline & $\begin{array}{l}\text { Oromotor } \\
\text { Accuracy }\end{array}$ & $\begin{array}{l}\text { Word } \\
\text { Recognition } \\
\text { Speed }\end{array}$ & $\begin{array}{l}\text { Decoding } \\
\text { Speed }\end{array}$ & $\begin{array}{l}\text { Listening } \\
\text { Comprehension }\end{array}$ \\
\hline Gender & $p=\begin{array}{r}.09 \\
\mathrm{p} \\
.40\end{array}$ & $p=.16$ & $p=.21$ & $p=.03$ \\
\hline Age & $\begin{array}{r}-.19 \\
\mathrm{p}=.09\end{array}$ & $\begin{array}{r}-.09 \\
p=.44\end{array}$ & $p=\begin{array}{r}.02 \\
\end{array}$ & $p=.58$ \\
\hline $\begin{array}{l}\text { Reading } \\
\text { Level }\end{array}$ & $p=\begin{array}{r}-.50 \\
p=.00\end{array}$ & $p=.00$ & $p=.00$ & $p=.01$ \\
\hline $\begin{array}{l}\text { Reading } \\
\text { Rate }\end{array}$ & $\begin{array}{r}-.35 \\
p=.00\end{array}$ & $p=.00$ & $p=.00$ & $\mathrm{p}=.23$ \\
\hline $\begin{array}{l}\text { Reading } \\
\text { Accuracy }\end{array}$ & $\begin{array}{r}-.13 \\
\mathrm{p}=.25 \\
\end{array}$ & $\mathrm{p}=.28$ & $p=.01$ & $\begin{array}{r}-.14 \\
p=.20\end{array}$ \\
\hline $\begin{array}{l}\text { Reading } \\
\text { Comprehension }\end{array}$ & $p=.30$ & $\begin{array}{r}-.24 \\
p=.03 \\
\end{array}$ & $\begin{array}{r}-.23 \\
p=.04 \\
\end{array}$ & $\mathrm{p}=.23$ \\
\hline Phrasing & $\begin{array}{r}-.45 \\
p=.00 \\
\end{array}$ & $\mathrm{p}=.56$ & $\mathrm{p}=.00$ & $p=.11$ \\
\hline Expression & $\begin{array}{r}-.36 \\
p=.00 \\
\end{array}$ & $\mathrm{p}=.47$ & $p=.00$ & $p=.31$ \\
\hline Prosody & $\begin{array}{r}-.45 \\
p=.00\end{array}$ & $p=.00$ & $\mathrm{p}=.00$ & $p=.14$ \\
\hline $\begin{array}{l}\text { Oromotor } \\
\text { Speed }\end{array}$ & $\mathrm{p}=.32$ & $p=.00$ & $p=.01$ & $p=\begin{array}{r}-.10 \\
p=.39\end{array}$ \\
\hline $\begin{array}{l}\text { Oromotor } \\
\text { Accuracy }\end{array}$ & & $p=\begin{array}{r}-.30 \\
p=00\end{array}$ & $\begin{array}{r}-.46 \\
p=.00 \\
\end{array}$ & $p=\begin{array}{r}-.34 \\
p=.00\end{array}$ \\
\hline $\begin{array}{l}\text { Word } \\
\text { Recognition } \\
\text { Speed }\end{array}$ & $\begin{array}{r}-.30 \\
p=.01\end{array}$ & & $\mathrm{p}=.00$ & $p=.08$ \\
\hline $\begin{array}{l}\text { Decoding } \\
\text { Speed }\end{array}$ & $\begin{array}{r}-.46 \\
p=.00\end{array}$ & $p=\begin{array}{r}.81 \\
.00\end{array}$ & & $p=.03$ \\
\hline $\begin{array}{l}\text { Listening } \\
\text { Comprehension }\end{array}$ & $p=.00$ & $p=.08$ & $p=.03$ & \\
\hline $\begin{array}{l}\text { Working } \\
\text { Memory }\end{array}$ & $p=\begin{array}{r}-.24 \\
p=.03\end{array}$ & $\mathrm{p}=.05$ & $p=.00$ & $p=.02$ \\
\hline $\begin{array}{l}\text { Syntax } \\
\text { Judgment }\end{array}$ & $\begin{array}{r}-.26 \\
p=.02\end{array}$ & $\mathrm{p}=.01$ & $p=.00$ & $p=.00$ \\
\hline $\begin{array}{l}\text { Rapid Serial } \\
\text { Naming }\end{array}$ & $p=\begin{array}{r}-.13 \\
=.25\end{array}$ & $p=.00$ & $p=.00$ & $p=.55$ \\
\hline
\end{tabular}


Bivariate Correlation Matrix (continued)

\begin{tabular}{|c|c|c|c|}
\hline & $\begin{array}{l}\text { Working } \\
\text { Memory }\end{array}$ & \begin{tabular}{|l|} 
Syntax \\
Judgment
\end{tabular} & $\begin{array}{l}\text { Rapid } \\
\text { Serial } \\
\text { Naming }\end{array}$ \\
\hline Gender & $\begin{array}{r}.05 \\
p=.68\end{array}$ & $\begin{array}{r}-.09 \\
p=.43\end{array}$ & $p=.17$ \\
\hline Age & $\mathrm{p}=.23$ & $p=\begin{array}{r}-.08 \\
\end{array}$ & $\mathrm{p}=\begin{array}{r}.03 \\
.77\end{array}$ \\
\hline $\begin{array}{l}\text { Reading } \\
\text { Level }\end{array}$ & $\mathrm{p}=.06$ & $p=.04$ & $p=.30$ \\
\hline $\begin{array}{l}\text { Reading } \\
\text { Rate }\end{array}$ & $p=.00$ & $p=.03$ & $\mathrm{p}=\begin{array}{r}.39 \\
.00\end{array}$ \\
\hline $\begin{array}{l}\text { Reading } \\
\text { Accuracy }\end{array}$ & $\mathrm{p}=.14$ & $\mathrm{p}=.32$ & $\mathrm{p}=\begin{array}{l}.33 \\
.00\end{array}$ \\
\hline $\begin{array}{l}\text { Reading } \\
\text { Comprehension }\end{array}$ & $\mathrm{p}=\begin{array}{r}.02 \\
.88\end{array}$ & $\mathrm{p}=.96$ & $\begin{array}{r}-.14 \\
p=.20\end{array}$ \\
\hline Phrasing & $\mathrm{p}=.07$ & $p=.02$ & $\mathrm{p}=\begin{array}{r}.29 \\
.01\end{array}$ \\
\hline Expression & $\mathrm{p}=.33$ & $p=\begin{array}{r}.09 \\
.42\end{array}$ & $\mathrm{p}=.26$ \\
\hline Prosody & $\mathrm{p}=.14$ & $p=.09$ & $\mathrm{p}=.31$ \\
\hline $\begin{array}{l}\text { Oromotor } \\
\text { Speed }\end{array}$ & $p=.18$ & $\begin{array}{r}-.01 \\
p=.90\end{array}$ & $p=.44$ \\
\hline $\begin{array}{l}\text { Oromotor } \\
\text { Accuracy }\end{array}$ & $\begin{array}{r}-.24 \\
p=.03\end{array}$ & $\begin{array}{r}-.26 \\
p=.02\end{array}$ & $\begin{array}{r}-.13 \\
\mathrm{p}=.25\end{array}$ \\
\hline $\begin{array}{l}\text { Word } \\
\text { Recognition } \\
\text { Speed }\end{array}$ & $p=.05$ & $\mathrm{p}=.28$ & $p=.00$ \\
\hline $\begin{array}{l}\text { Decoding } \\
\text { Speed }\end{array}$ & $\mathrm{p}=.00$ & $p=.00$ & $p=.56$ \\
\hline $\begin{array}{l}\text { Listening } \\
\text { Comprehension }\end{array}$ & $p=.02$ & $\mathrm{p}=.00$ & $\begin{array}{r}-.07 \\
\mathrm{p}=.55\end{array}$ \\
\hline $\begin{array}{l}\text { Working } \\
\text { Memory }\end{array}$ & & $\mathrm{p}=.03$ & $p=.20$ \\
\hline $\begin{array}{l}\text { Syntax } \\
\text { Judgment }\end{array}$ & $\mathrm{p}=.03$ & & $\begin{array}{r}-.01 \\
p=.96\end{array}$ \\
\hline $\begin{array}{l}\text { Rapid Serial } \\
\text { Naming }\end{array}$ & $\mathrm{p}=.20$ & $\begin{array}{r}-.01 \\
p=.96\end{array}$ & \\
\hline
\end{tabular}




\section{Appendix G}

\section{$\underline{\text { Partial Correlation Matrix }}$}

\begin{tabular}{|c|c|c|c|c|c|}
\hline & $\begin{array}{l}\text { Reading } \\
\text { Rate }\end{array}$ & $\begin{array}{l}\text { Reading } \\
\text { Accuracy }\end{array}$ & $\begin{array}{l}\text { Reading } \\
\text { Comprehension }\end{array}$ & Phrasing & Expression \\
\hline Reading Rate & & $p=.01$ & $\begin{array}{r}-.02 \\
p=.88\end{array}$ & $p=\begin{array}{r}.65 \\
p=00\end{array}$ & $\mathrm{p}=.38$ \\
\hline $\begin{array}{l}\text { Reading } \\
\text { Accuracy }\end{array}$ & $p=.01$ & & $\begin{array}{r}-.29 \\
p=.01 \\
\end{array}$ & $p=.20$ & $p=.06$ \\
\hline $\begin{array}{l}\text { Reading } \\
\text { Comprehension* }\end{array}$ & $\begin{array}{r}-.02 \\
p=.88\end{array}$ & $\begin{array}{r}-.29 \\
p=.01\end{array}$ & & $p=.03$ & $\begin{array}{r}-.01 \\
p=.97\end{array}$ \\
\hline Phrasing* & $p=.00$ & $p=.20$ & $\begin{array}{r}.03 \\
p=.78\end{array}$ & & $p=.43$ \\
\hline Expression* & $p=.00$ & $p=.60$ & $\begin{array}{r}-.01 \\
p=.97\end{array}$ & $p=.43$ & \\
\hline Oromotor Speed & $\mathrm{p}=. \begin{array}{l}.10 \\
.40\end{array}$ & $\begin{array}{r}.19 \\
\mathrm{p}=.09\end{array}$ & $\begin{array}{r}-.05 \\
p=.66\end{array}$ & $p=\begin{array}{r}.05 \\
.66\end{array}$ & $\begin{array}{r}-.06 \\
p=.59 \\
\end{array}$ \\
\hline $\begin{array}{l}\text { Oromotor } \\
\text { Accuracy }\end{array}$ & $\begin{array}{r}-.09 \\
p=.42\end{array}$ & $\begin{array}{r}-.12 \\
p=.30\end{array}$ & $p=\begin{array}{r}.09 \\
.42\end{array}$ & $\begin{array}{r}-.18 \\
p=.10\end{array}$ & $\begin{array}{r}-.06 \\
p=.63\end{array}$ \\
\hline $\begin{array}{l}\text { Word } \\
\text { Recognition } \\
\text { Speed }\end{array}$ & $p=.00$ & $p=.02$ & $p=.03$ & $\mathrm{p}=.39$ & $\mathrm{p}=.27$ \\
\hline Decoding Speed & $p=.00$ & $p=.02$ & $p=.01$ & $p=.00$ & $\begin{array}{r}.09 \\
\mathrm{p}=.45 \\
\end{array}$ \\
\hline $\begin{array}{l}\text { Working } \\
\text { Memory }\end{array}$ & $p=.01$ & $p=.25$ & $\begin{array}{r}.01 \\
=.94\end{array}$ & $p=.25$ & $\begin{array}{r}-.00 \\
p=.98\end{array}$ \\
\hline $\begin{array}{l}\text { Listening } \\
\text { Comprehension }\end{array}$ & $\begin{array}{r}-.02 \\
p=.88\end{array}$ & $\begin{array}{r}-.18 \\
p=.10\end{array}$ & $p=.03$ & $p=.02$ & $\begin{array}{r}-.04 \\
p=.70\end{array}$ \\
\hline Syntax Judgment & $p=.18$ & $\mathrm{p}=.08$ & $\begin{array}{r}-.04 \\
p=.75\end{array}$ & $\begin{array}{r}.16 \\
p=.16\end{array}$ & $\begin{array}{r}-.04 \\
p=.72\end{array}$ \\
\hline
\end{tabular}

* transformed variables 
$\underline{\text { Partial Correlation Matrix (continued) }}$

\begin{tabular}{|c|c|c|c|c|c|}
\hline & $\begin{array}{l}\text { Oromotor } \\
\text { Speed }\end{array}$ & $\begin{array}{l}\text { Oromotor } \\
\text { Accuracy }\end{array}$ & $\begin{array}{l}\text { Word } \\
\text { Recognition } \\
\text { Speed }\end{array}$ & $\begin{array}{l}\text { Decoding } \\
\text { Speed }\end{array}$ & $\begin{array}{l}\text { Working } \\
\text { Memory }\end{array}$ \\
\hline Reading & .10 & -.09 & .56 & .38 & .31 \\
\hline Rate & $\mathrm{p}=.40$ & $\mathrm{p}=.42$ & $\mathrm{p}=.00$ & $\mathrm{p}=.00$ & $p=.01$ \\
\hline Reading & .19 & -.12 & .25 & .27 & .13 \\
\hline Accuracy & $\mathrm{p}=.09$ & $p=.29$ & $\mathrm{p}=.02$ & $\mathrm{p}=.02$ & $p=.25$ \\
\hline Reading & -.05 & .09 & -.24 & -.28 & .01 \\
\hline Comprehension* & $p=.66$ & $\mathrm{p}=.42$ & $\mathrm{p}=.03$ & $\mathrm{p}=.01$ & $p=.99$ \\
\hline \multirow[t]{2}{*}{ Phrasing* } & .05 & -.18 & .39 & .31 & .13 \\
\hline & $\mathrm{p}=.66$ & $p=.10$ & $p=.00$ & $\mathrm{p}=.00$ & $p=.25$ \\
\hline \multirow[t]{2}{*}{ Expression* } & -.06 & -.12 & .27 & .09 & -.00 \\
\hline & $\mathrm{p}=.59$ & $p=.27$ & $p=.02$ & $\mathrm{p}=.45$ & $\mathrm{p}=.98$ \\
\hline \multirow[t]{2}{*}{ Oromotor Speed } & & .29 & .21 & .17 & .10 \\
\hline & & $p=.01$ & $p=.06$ & $\mathrm{p}=.13$ & $p=.38$ \\
\hline Oromotor & .29 & & -.06 & -.20 & -.18 \\
\hline Accuracy & $\mathrm{p}=.01$ & & $p=.63$ & $\mathrm{p}=.07$ & $\mathrm{p}=.11$ \\
\hline Word & .21 & -.06 & & .74 & .13 \\
\hline $\begin{array}{l}\text { Recognition } \\
\text { Speed }\end{array}$ & $\mathrm{p}=.06$ & $\mathrm{p}=.63$ & & $\mathrm{p}=.00$ & $\mathrm{p}=.24$ \\
\hline \multirow[t]{2}{*}{ Decoding Speed } & .17 & -.20 & .74 & & .27 \\
\hline & $p=.13$ & $\mathrm{p}=.07$ & $\mathrm{p}=.00$ & & $p=.02$ \\
\hline Working & .10 & -.18 & .13 & .27 & \\
\hline Memory & $\mathrm{p}=.38$ & $\mathrm{p}=.11$ & $\mathrm{p}=.24$ & $\mathrm{p}=.02$ & \\
\hline Listening & -.18 & -.24 & .06 & .07 & .22 \\
\hline Comprehension & $\mathrm{p}=.11$ & $\mathrm{p}=.03$ & $\mathrm{p}=.58$ & $\mathrm{p}=.51$ & $p=.05$ \\
\hline Syntax & -.08 & -.17 & .19 & .23 & .20 \\
\hline Judgment & $\mathrm{p}=.48$ & $\mathrm{p}=.12$ & $\mathrm{p}=.08$ & $\mathrm{p}=.04$ & $\mathrm{p}=.08$ \\
\hline
\end{tabular}


Partial Correlation Matrix (continued)

\begin{tabular}{|c|c|c|}
\hline & $\begin{array}{l}\text { Listening } \\
\text { Comprehension }\end{array}$ & $\begin{array}{l}\text { Syntax } \\
\text { Judgment }\end{array}$ \\
\hline $\begin{array}{l}\text { Reading } \\
\text { Rate }\end{array}$ & $\begin{array}{r}-.02 \\
p=.88\end{array}$ & $p=\begin{array}{r}.15 \\
.18\end{array}$ \\
\hline $\begin{array}{l}\text { Reading } \\
\text { Accuracy }\end{array}$ & $\begin{array}{r}-.18 \\
p=.10\end{array}$ & $\mathrm{p}=.46$ \\
\hline $\begin{array}{l}\text { Reading } \\
\text { Comprehension* }\end{array}$ & $p=.03$ & $p=\begin{array}{r}-.04 \\
p=.75\end{array}$ \\
\hline Phrasing* & $\mathrm{p}=.87$ & $p=.16$ \\
\hline Expression* & $\begin{array}{r}-.04 \\
p=.70 \\
\end{array}$ & $\begin{array}{r}-.04 \\
p=.72 \\
\end{array}$ \\
\hline $\begin{array}{l}\text { Oromotor } \\
\text { Speed }\end{array}$ & $\mathrm{p}=\begin{array}{r}-.18 \\
\mathrm{y}\end{array}$ & $\begin{array}{r}-.08 \\
p=.48 \\
\end{array}$ \\
\hline $\begin{array}{l}\text { Oromotor } \\
\text { Accuracy }\end{array}$ & $\mathrm{p}=. .24$ & $\begin{array}{r}-.13 \\
p=.12 \\
\end{array}$ \\
\hline $\begin{array}{l}\text { Word } \\
\text { Recognition } \\
\text { Speed }\end{array}$ & $\mathrm{p}=.06$ & $p=.08$ \\
\hline $\begin{array}{l}\text { Decoding } \\
\text { Speed }\end{array}$ & $\mathrm{p}=\begin{array}{r}.07 \\
.51\end{array}$ & $\mathrm{p}=\begin{array}{r}.23 \\
.04 \\
\end{array}$ \\
\hline $\begin{array}{l}\text { Working } \\
\text { Memory }\end{array}$ & $p=.05$ & $p=.08$ \\
\hline $\begin{array}{l}\text { Listening } \\
\text { Comprehension }\end{array}$ & & $p=\begin{array}{r}.48 \\
.00\end{array}$ \\
\hline $\begin{array}{l}\text { Syntax } \\
\text { Judgment }\end{array}$ & $p=\begin{array}{r}.48 \\
.00\end{array}$ & \\
\hline
\end{tabular}

* transformed variables 


\section{BIBLIOGRAPHY}

Allington, R. L. (1983). Fluency: the neglected reading goal. The Reading Teacher, 556-561.

Anderson, R. C., Wilson, P. T., \& Fielding, L. G. (1988). Growth in reading and how children spend their time outside of school. Reading Research Quarterly, 23.

Baddeley, A. D., Thomson, N., \& Buchanan, M. (1975). Word length and the structure of short term memory. Journal of Verbal Learning and Verbal Behavior, 14, 575-589.

Ball, E. W., \& Blachman, B. A. (1991). Does phoneme awareness training in kindergarten make a difference in early word recognition and developmental spelling? Reading Research Quarterly, 26, 49-66.

Bowers, P. G. (1993). Test reading and re-reading: Determinants of fluency beyond word recognition. Journal of Reading Behavior, 25(2), 135-153.

Bowers, P. G., Sunseth, K., \& Golden, J. (1999). The route between rapid naming and reading progress. Scientific Studies of Reading, 3(1), 31-53.

Catts, H. W. (1991). Early identification of dyslexia: evidence from a follow-up study of speech-language impaired children. Annals of Dyslexia, 41, 163-177.

Catts, H.W. (1986). Speech production/phonological deficits in readingdisordered children. Journal of Learning Disabilities, 19 , 504-508.

Cecconi, C. P., Hood, S. B., \& Tucker, R. K. (1977). Influence of reading level difficulty on the difficulties of normal children. Journal of Speech and Hearing Research. $\underline{20}, 475-484$.

Chomsky, C. (1976). After decoding: What? Language Arts, 53, 288-296. 
Cowen, N. (1996). Short term memory, working memory, and their importance in language processing. Topics in Language Disorders, 17(1), 1-18.

Decker, S.N. (1989). Cognitive processing rates among disabled and normal reading young adults: a nine-year follow-up study. Reading and Writing: An Interdisciplinary Journal, $\underline{2}, 123-134$.

Denckla, M. B., \& Cutting, L. E. (1999). History and significance of rapid automatized naming. Annals of Dyslexia, 49, 29-42.

Denckla, M.B., \& Rudel, R. (1976). Rapid "automatized" naming (R.A.N.): dyslexia differentiated from other learning disabilities. Neuropsychologia, 14, 471-479.

Dowhower, S. L. (1987). Effects of repeated reading on second-grade transitional reader's fluency and comprehension. Reading Research Quarterly, 22, 389-406.

Ehri, L. C., \& McCormick, S. (1998). Phases of word learning: implications for instruction with delayed and disabled readers. Reading and Writing Quarterly: Overcoming Learning Difficulties, 14, 135-163.

Elbro, C. (1997). Different language abilities predict poor and good reading in the early grades. Paper presented at the AERA meeting, Chicago.

Faulkner, H. J., \& Levy, B. A. (1999). Fluent and nonfluent forms of transfer in reading: words and their message. Psychonomic Bulletin and Review, 6(1), 111-116.

Fleischer, L. S., Jenkins, J. R., \& Pany, D. (1979). Effects on poor readers comprehension of training in rapid decoding. Reading Research Quarterly, 15, 30-48.

Fowler, A (1988). Grammaticality judgments and reading skill in grade two. Annals of Dyslexia, 38 (73-94). 
Fuchs, L.S., Fuchs, D., Hosp, M.K. \& Jenkins, J.R. (2001). Oral reading fluency as an indicator of reading competence: a theoretical, empirical, and historical analysis. Scientific Studies of Reading, $\underline{5}(3), 239-256$.

Fuchs, L.S., Fuchs, D., \& Maxwell, L. (1988). The validity of informal reading comprehension measures. Remedial and Special Education, $\underline{9}(2), 20-28$.

Gough, P. B., \& Tunmer, W. E. (1986). Decoding, reading, and reading disability. RASE: Remedial and Special Education, 7, 6-10.

Hammill, D.D., \& Newcomer, P.L.(1997). Test of Language Development Intermediate: Third Edition. Austin, TX: Pro-Ed.

LaBerge, D., \& Samuels, S. J. (1974). Toward a theory of automatic information processing in reading. Cognitive Psychology, 6, 293-323.

Leslie, L., \& Caldwell, J. (2001). Qualitative Reading Inventory - Third Edition New York: Longman.

Levy, B. A., Abello, B., \& Lysynchuk, L. (1997). Transfer from word training to reading in context: Gains in reading fluency and comprehension. Learning Disability Quarterly, 20, 173-188.

Lezak, M. D. (1995). Neuropsychological Assessment - Third Edition. New York: Oxford University Press.

Liberman, I. Y., Shankweiler, D., Fischer, F. W., \& Carter, B. (1974). Explicit syllable and phoneme segmentation in the young child. Journal of Experimental Child Psychology, 18, 201-212.

Liberman, I. Y., Shankweiler, D., \& Liberman, A. M. (1989). The alphabetic principle and learning to read. In D. Shankweiler \& I. Y. Liberman (Eds.), Phonology and 
Reading Disability: solving the reading puzzle (pp. 1-33). Ann Arbor, MI: University of Michigan Press.

Linn, B.M., Stanovich, K.E., \& Stringer, K.R. (1999). Choosing to read: effects of first-grade phonics on fourth-grade preferences. The International Dyslexia Association $50^{\text {th }}$ Anniversary Conference: Chicago, IL.

Logan, G.D. (1997). Automaticity and reading: perspectives from the instance theory of automatization. Reading and Writing Quarterly: Overcoming Learning Difficulties, 13 (123-146).

Lovett, M. W. (1984). A developmental perspective on reading dysfunction: accuracy and rate criteria in the subtyping of dyslexic children. Brain and Language, 22, $67-91$.

Meyer, M. S., \& Felton, R. H. (1999). Repeated reading to enhance fluency: old approaches and new directions. Annals of Dyslexia, 49, 283-306.

Montgomery, D. (1981). Do dyslexics have difficulty accessing articulatory information? Psychological Research, 43, 235-243.

National Institute of Child Health and Human Development (2000). Report of the National Reading Panel. Teaching Children to Read: An evidence-based assessment of the scientific research literature on reading and its implications for reading instruction (NIH-Publication No. 00-4769), Washington, DC: U.S. Government Printing Office. Nicholson, R.I., \& Fawcett, A.J. (1990). Automaticity: a new framework for dyslexia research? Cognition, $\underline{35}$ (2), 29-48. 
Perfetti, C. A., \& Hogaboam, T. (1975). The relationship between single word decoding and reading comprehension skill. Journal of Educational Psychology, 67(4), 461-469.

Perfetti, C. A., \& Lesgold, A. M. (1979). Coding and comprehension in skilled reading and implications for reading instruction. In L. B. Resnick \& P. A. Weaver (Eds.), Theory and Practice of Early Reading (Vol. 1, pp. 57-84). Hillsdale, NJ: Lawrence Erlbaum Associates, Publishers.

Rapala, M.R., \& Brady, S. (1990). Reading ability and short-term memory: The role of phonological processing. Reading and Writing, 2, 1-25.

Rasinski, T. V. (1989). Adult readers' sensitivity to phrase boundaries in texts. The Journal of Experimental Education, 58, 29-40.

Russell, E. D. (2000). An initial exploration of the relationship between word recognition fluency and passage reading fluency, and associated speech perception abilities, unpublished data, University of Rhode Island, Kingston, RI.

Samuels, S. J. (1979). The method of repeated readings. The Reading Teacher, $\underline{32}, 402-408$.

Sattler, J. M. (1988). Assessment of Children - Third Edition. San Diego, CA: Jerome M. Sattler

Scarborough, H. (1998). What is Rapid Automatic Naming. Paper presented at the Society for the Scientific Studies of Reading, Montreal, Canada.

Schrieber, P. A. (1980). On the acquisition of reading fluency. Journal of Reading Behavior, 12(3), 177-186. 
Shankweiler, D. (1989). How problems of comprehension are related to difficulties in decoding. In D. Shankweiler \& I. Liberman (Eds.), Phonology and Reading Disability (pp. 35-68). Ann Arbor, MI: University of Michigan Press.

Shankweiler, D., Liberman, I.Y., Mark, L.S., Fowler, C.A., \& Fischer, F.W. (1979). The speech code and learning to read. Journal of Experimental Psychology: Human Learning and Memory, $\underline{5}, 531-545$.

Shankweiler, D., Lundquist, E., Katz, L., Stuebing, K. K., Fletcher, J. M., Brady, S., Fowler, A., Dreyer, L. G., Marchione, K. E., Shaywitz, S. E., \& Shaywitz, B. A. (1999). Comprehension and Decoding: Patterns of association in children with reading difficulties. Scientific Studies of Reading, 3(1), 69-94.

Snyder, L. S., \& Downey, D. M. (1995). Serial rapid naming skills in children with reading disabilities. Annals of Dyslexia, 45, 31-49.

Stanovich, K. E. (1986). Matthew effects in reading: some consequences of the individual differences in the acquisition of literacy. Reading Research Quarterly, 21, 360406.

Stanovich, K.E. (1988). Explaining the differences between the dyslexic and garden-variety poor reader: The phonological core variable-difference model. Journal of Learning Disabilities, 21, 590-612.

Stone, B., \& Brady, S. (1995). Evidence for deficits in basic phonological processes in less-skilled readers. Annals of Dyslexia, 45, 51-78.

Tan, A., \& Nicholson, T. (1997). Flashcards Revisited: training poor readers to read words faster improves their comprehension of text. Journal of Educational Psychology, 89(2), 276-288. 
Torgesen, J.K., Wagner, R.K., \& Rashotte, C.A. (1999). Test of Word Reading Efficiency. Austin, TX: Pro-Ed.

Torgesen, J. K., Wagner, R. K., \& Rashotte, C. A. (1997). Prevention and remediation of severe reading disabilities: keeping the end in mind. Scientific Studies of Reading, 1(3), 217-234.

Torgesen, J.K., Rashotte, C.A., \& Alexander, A.W. (2001). Principles of fluency instruction in reading: relationships with established empirical outcomes. in M. Wolf (Ed.) Dyslexia, Fluency, and the Brain. Timonium, MD: York Press.

van den Bosch, K., van Bon, W., \& Schreuder, R. (1995). Poor readers' decoding skills: Effects of training with limited exposure duration. Reading Research Quarterly, $\underline{30}, 110-125$.

Wagner, R.K., Torgesen, J.K., \& Rashotte, C.A. (1999). Comprehensive Test of Phonological Processing. Austin, TX: Pro-Ed.

Wechsler, D.A. (1995). Wechsler Intelligence Scale for Children - Third Edition. San Antonio: The Psychological Corporation.

Wolf, M. (1997). A provisional, integrative account of phonological and naming speed deficits in dyslexia: implications for diagnosis and intervention. In B. Blachman (Ed.), Cognitive and Linguistic Foundations of Reading Acquisition: Implications for intervention research . Hillsdale, NJ: Erlbaum.

Wolf, M. and Bowers, P.G. (1999). The double deficit hypothesis for the developmental dyslexias. Journal of Educational Psychology, 91, 415-438. 
Wolff, P. H., Michel, G. F., \& Ovrut, M. (1990). The timing of syllable repetitions in developmental dyslexia. Journal of Speech and Hearing Research, 33, 281289.

Young, A., \& Bowers, P. G. (1995). Individual differences and text difficulty determinants of reading fluency and expressiveness. Journal of Experimental Child Psychology, 60, 428-454. 